\title{
DOCUMENTOS DO ARQUTVO HISTÓRICO DO RIO GRANDE DO SUL
} (Correspondéncia do Consulado da Espanha - Série II)

A correspondència aqui incluida, em cópia paleográfica, foi recolhida pelos seguintes alunos do Curso de História do Instituto de Filosofia e Ciéncias Humanas da PUC/RS: Agripino Alcidio Coelho, Alberto Tofani, Alda Gravina de Moraes, Alda Maria Ferreira do Amaral, Alice Fátima Amorim Andrade, Alice Medeiros, Anna Maria T, Corbetta, Carlos Alberto Carvalho Benitz, Carolina Miranda do Nascimento, Elisabete Lopes Pinheiro, Ero Braun, Iara Silvia de Moraes Cauduro, Ione Terezinha Castro Dubal, Jane de Lemos Geidel e Jane Erminda Passuello, sob a direçăo do Professor Moocyr Flores. 


$$
\text { Ex. }{ }^{\mathrm{mo}} \text { Sof }
$$

El abajo firmado Vice Consul de S.M. Católica y Consul de la Republica de Chile, tiene el gusto de acusar recepcion delas Notas de V.E. dedata de 4 y 27 del mes pp. ${ }^{\circ}$ Febrero de este afho.

En esta, acompanaba V.E. circular impresa del Decreto $\pi^{\circ} 855$ de 8 de Noviembre ultimo, que declara las esenciones y atribuciones de los Agentes Consulares Extrangeros en el Imperio, para la Administracion delas herencias: $-y$ en aquel, los esclarecimientos del farol de fierro, colocado y encedido por primera vez en esta Barra, el 18 de Enero del corriente año, para los fines de utilidad a lanavegacion.

El que suscrive, rinde a V. E. las mas expresivas gracias, por la fineza y atenta bondad desu demonstracion.

Dios Guarde â V. Ex, ${ }^{\text {a }}$ muchos años.

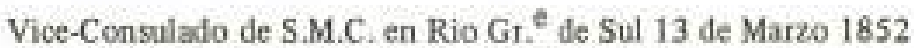

Ex. ${ }^{\text {mo }}$ Sor V. Presidente dela Provincia.

Don Luis Alves Leite V. Oliveira Bello

Pablo de Goycoechea

V. Consul

D. JOĀo PEREIRA MACHADO, Vice Consul de S.M.C, en Porto Alegre

\section{FILIACION}

Edad

Estatura:

Cabello:

Ojos:

Cejas:

Nariz:

Barba:

Color:

Ocupacion:

Estado:

Firma:

Pablo Febres

Gratis
CERTIFICO que Pablo Frebes Capdebila es Espafiol natural de Cataluna lo cual ha justificado en este Vice Consulado de mi cargo, y para que pueda hacerlo constar, doy el presente firmado de mi mano y con el Sello del Consulado

Porto Alegre, 24 de Agosto de 1854 


$$
\mathrm{uI}^{\mathrm{mo}} \in \mathrm{Exm}{ }^{0} \mathrm{Señ} .
$$

Tendo por duas vezes este Vice Consulado dirigindo-se ao Sen D. ${ }^{\text {or Juis }}$ Municipal de Pelotas rogando-the que o instruir do estado em que se acha a arrecadaeșo a que procedeu dos bens do finado sudito el Hespanhol Manuel Lavalle, e quem é o curador nomeado a herança, isto a fum de poder este Vice Consulado prestar a Legação Hespanhola as informaçôes que the foram pediúos, e nāo tendo o ditto Señ. Juiz Municipal dignado-se ate hoje, de dar resposta alguma aos referidos oficios cumpre ao infrascripto Vice Consul de S. M. Catholica recorrer a V. Ex. ${ }^{3}$ pretendendo as necessarias providencias, a bem de lhe serem daklas pelo referido juizo os esclarecimentos pedidos.

O abaixo assignado aproveita a oceasiâo de Saudar à V. Ex. ${ }^{2}$ com perfeita consideraçáo e apreço.

Deos guarde à V. Ex. ${ }^{\text {a }}$ muitos annos. Vice Consulado Hespanhol na cidade de Rio Grande à 15 de Novernibro de 1854.

Ao III. ${ }^{\text {mo }}$ e Ex. ${ }^{\text {mo }}$ Señ. D. or Joāo Luis Vieira Cansansio de Sinimbu.

Digno Presidente da Provincia

Paulo Goycoeches

V. Consul

1855

Rio Grande

Vice Consulado

$$
\text { Exm. }{ }^{\circ} \text { Sór. }
$$

Al abajo firmado le acomparia el pesar de no haver acusado recibo á debido tiempo de los atentos oficios de V. Ex ${ }^{\mathrm{a}}$ datados de 23 de Noviembre, Circular de 16 de Diziembre y 28 del mismo, del año pp. ${ }^{\circ}$ por haberse hallado algo enfermo,

Empeso de esta circumztancia, hoy tiene la complacència de dirigirse fí V. Ex. ${ }^{a}$, rindiendole expresivar gracias:

En virtud delas crdenes de V. E, para que el Sõ̀. Juez Municipal y de ausentes de Pelotas, se sirviere dar à este Vice-Consulado los esclarecimientos que pedia á respecto del fallecido intestado español Manuel Lavalle, dicho Sor. fue atento, en satisfacer los deseos del Vic Consulado y en la ocasion, tambien le acusa recibo is su oficio, y no haverlo lsecho mas antes, ha motivado la eausa que manifiesta arriba, de sua aiterada salud. 
El oficio de V. Ex. ${ }^{a}$ de 28 de Distembre confirma haber dado el referido Sur. Juez Municipal, los informes pedidos del espolio del mencionado finado Manuel Lavalle.

La circular de 16 de Disiembre, decfara los embarazos que suele presentar el reclutamiento voluntário à que se oferecen subditos de Naciones extrangeras, que se alistan en el Egercito y Armada Imperial Brasileira; lo que dá motivos á algunos reclamos por parte de los Agentes Consulares.

El que suscribe, está convencido que el que ha contrahido un empento, debe de cumplit, y que no puede ingerirse sobre un Convenio que por si, ya forma pacto.

Esto no obsta para que el abajo firmado se tome la osadia de hacer á V. Ex. ${ }^{a}$ una obscervacion que prende algo a lo que va referido.

Un Capitan de buque mercante brasileiro, pretende un marinero estrangero, este, lo contrata por exemplo para carga y descarga del barco, de este Puerto para el Rio de Janciro, o vice versa - precisa para esta operacion Certificado ó licencin de la Agencia Consular, para la capitania de Puerto - se le espide sin impedimento y queda por conseguiente entolado.

El buque llega á su destino, y le dá el caṕ. el billete de desembarque que actedita el cumplimiento de ajuste, $y$ di este, tripulante estrangero, lo toman em Puerto para una leva, 6 to extraen de a bordo sin cumplir su trato, à un buque de Guerra; no tendri el derecho de reclamar á sua corsul, y este, no podrá referentar en tal caso, a la Autoridade competente del Pais?

0 , el met hecho de servir simple y temporariamente, este tripulante, en navio mercantil brasileiro, lo constituye á una obligacion en el servicio del Egercito o Armada Brasileira?

Sờr. El que suscribe ha tenido motivos de ingerirse en estos casos, con algunos ilustres Gefes de la Armada Imperial, y ha tenido ta satisfacion de ser correspondido con finesa a sus pedidos, pero ha tropesado con alguien, que lo viso por deferencia: portanto suplico a V. Ex. ${ }^{a}$ se digne manifestarle si habrá incoveniente para los reclamos de esta clase en lo futuro.

El que firma tiene el honot de saludar à V. Ex. ${ }^{a}$ a quien Dios Guarde muchos años. Ciudad del Rio Grande do Sul 15 de Enero de 1855.

Ex. mo Sor. Don Joăo Luis Vieira Cansançăo de Sinnimbu

Digno Presidente ó la Provincia

Pablo Goycoechea 
Vice Consulado de

S.M. Catholica em P. ${ }^{\text {to }}$ Alegre

Tendo no dia 26 do passado sido recrutados violentamente na Cidade do Rio Grande, e alyembarcados no vapor de guerra Amelia, que se acha n'este Porto, os subuitos de S.M. Catholica, Domingos Antonio Francisco, e Fernando Rodrigues, cujos titulos de Nacionalidade acharo-se inclusos.

O abaixo assignado Vice Consul de S.M.C. r'esta Cidade tem a honra de reclamar de S. Ex. ${ }^{\text {cia }}$ o Srit Presidente da Provincia as competentes ordens ao Comandante daquelle vapor para pór immediatamente em sua plena liberdade aquelles subditos de S.M. Catholica.

estima.

$\mathrm{O}$ abaixo assignado tem a honra de reiterar a $\mathrm{S}$. Ex. ${ }^{\text {cia }}$ sua alta consideraçăo e

Deos Guarde a V. Ex. cia muittos annos.

Vice Consulado de S.M.C. $=$ em Porto Alegre de 6 de Fevereino de 1856.

III. ${ }^{\mathrm{mo}}$ Ex. ${ }^{\text {mo }}$ Sefir Barío

de Muritiba $=$ Dignissimo

Presidente da Provincia

Jō̄o Pereira Machado

Vice Consul

III. ${ }^{\mathrm{mo}} \mathrm{e} \mathrm{Ex}{ }^{\mathrm{mo}} \mathrm{SOr}$

Uma desagradavel occorrencia que teve lugar n'esta Cidade entre à Alfandega e à Polaca Hespanhola "Maria Uoveras me levão à presença de V. Ex." para representar contra o que me pareceu falta de attenção, à bandeira d'Hespanha e excesso commetido.

Denunciada à Polaca de levantar ancora, mediante os competentes despachos e que conduzia couros extraviados à direitos, foi logo arrestada pela Alfandega e entregue à descarga para conferir seu carregamento, o quesendo executado invadia-se à propriedade hespanhola e segais-se a apprehensão della e de sua carga em geral, sem quese desse o menor conhecimento de cousa alguma â este Consulado senăo junto no momento da descarga. Parece me Ex. ${ }^{\text {mo }}$ Sồ, que neste procedimento houve departe d'Alfandega uma falta de attençjo e cortezia para com a bandeira hespanhola, porque os usos c costumes admitidos entre as Naçōes amigas, estabelecem n'este cazo, a communicaçăo previa de arrestamento e mais diligéncias de detençũo as Agente Consular respectivo, etāobem repetia excesso desde que năo só se apprehenderåo cos couros subtraides aos direitos, mass tambem os quese acharäo devidamente despachados: visto que a lei só falla d'aquelles 
enllo destes. Mas não parou aqui o excesso, Ex, mo Sõr, processłđa à apprehensฐ̄o, forão condenados os couros que nĩ̃o tinhlio precedido despacho e com elles a Propria embarcaçån:

A sentença proferida à tal respeito por o Sōr Inspector d'Alfandega, a considero - Injusta, Illegar e Contradietoria endo be por isso minhaintensăo faltar ao respeito devidal Auctoridade, porque tributando-lhe tanto quasto sou capaz; posso equivocar me, porem estou convencido de queo Sor Inspector, ha errado portodos os inctivos de que os homens sẫo susceptiveis; $e$ por isso provoco todo o interesse que ella inspira, $e$ observara V.Ex. ${ }^{a}$ - um theatro de tristeza - um quadro sensivel, uma irregularidade talo cruel em quese abisma aos Proprietarios do navio hespanhol "-Maria Loveras" - A - embarcaç̄io eu creio que nẳo pode soffrer uma tal condemnaçǟo; porque nẳo devendo punir-se um crime com duas penas, a condemnaç̌̃o daperda dos couros subtraidos aos direitos e à multa igual à metade dovalor d'elles, - ế a ínica pena que as leis do pais impōe en casos taes.

Dirigindo-me portanto i V. Ex. ${ }^{2}$ eu conto q. ${ }^{e}$ V. Ex. ${ }^{2}$ procedendo as informaçöes necessarias dignar-se-ha prover à respeito com a costumada justiça-

Tenho a satisfacção de tributar a V, Ex, ${ }^{a}$ as homenagens derespeito y consideraçăo. maio de 1856 .

Deos Guarde à V. Ex. ${ }^{a}$ muittos annos - Vice Consulado d'Hespanha á 3 de III. ${ }^{\mathrm{m}}$ e Ex. ${ }^{\mathrm{mo}}$ Sör Conselheiro

Don Jeronimo Francisco Coelho

Presidente da Provincia

Porto Alegre-

Pablo de Goycoechea

V.Consul d'Hespanha

O Săr Segundo Escriptuario servindo de Escrivåo do processo de contrabando e apprehenșăo da Polaca Hespanhola = Maria Loberís w passe por certidāo junto a esta oxdem, extrahida dos respectivos Autos a decisão que juigou procedente apprehensăo da Carga ñ̄o despechada e da mesma Polaca, conforme pede o Consul de Sua Magestade Catholica nesta Cidade Pablo Goycochez, sem prejuizo dos respectivos emolamentos pertencentes a Fazenda Nacional.

Alfandega e Meza do Consulado do Rio Grande, 30 de Abril de 1856. 
Certifíco que a decizĩo que o Supplicante pede por certidão, he do theor seguinte $=$ Vistos estes autos, achase nelles provado que Francisco Casals, Capitão da polaca hespanhola - Maria Lloberas - tendo dado ao manifesto no dia vinte e oito de março, seis mil tresentos noventa e trez couros vaceuns seccos limpos, cento cincoenta c um ditos avariados, duzentos cincoenta e dous ditos de temeiro limpos, e quatorze fardos com trezentos sessenta e cinco arrobas de garras de couro, despachou a sua embarcaçäo nesse mesmo dia com destino a Cadix e Terragona; e que, passando-se, por denuncia e deligencias a que em virtude della mandei proceder, a conferit o carregamento, verificou-se haver o dito capitão da polaca hespanhola Maria Loweras, Francisco Cassls, feito embarcar por contrabando e recebido a seu bordo, sem despacho e previo pagamento dos direitos de exportaçăo, mil e tresentos couros vaccuns seccos limpos, e cento vinte e trez. arrobas e vinte 'uma libra de garras de couro, como consta do termo a folhas; e não tendo-se alkgado circunstancia alguma em defeza dos factos criminozos denunciados e realizados como se mostra dos autos a folhas vinte cinco, risque follas vinte oito; julgo, por tanto procedente a apprehensão dos mil e trezentos couros vaccuns limpos, e das cento vinte e trez arrobas e vinte uma libras de garras de couros, que demais foram encontradas; e assim mais, em consequencia de conduzir generos extraviados a direitos nacionaes; julgo igualmente procedente a apptehensăo da polaca hespahola Maria Uoberas, em conformidade do que dispoem o artigo cento noventa e oito do regulamento de trinta de maio de mil oito centos trinta e seis, combinado com os artigos duzentos oitenta e quatro, e duzentos noventa e dous de vinte dous de Junho do mesmo anno, e absolvo e mando que sejam entregues aos seus respectivos donos os seis mill trezentos e noventa e trez couros vaccuns seccos limpos, cento cincoenta e um ditos avariados, duzentos cincoenta e dous ditos de temeiro limpos, e assim comotantos fardos de garras quantos bastem paraprefazerem o pezo de trezentas sessenta e cinco artobas, em razdo de se achar tudo legalmente despachado, e haver pago os respectivos direitos de exportação; e condemno, em virtude do artigo cento setenta e sete do Codigo Criminal, a Franciseo Casals, capitho da polaca hespanhola Maria Lloberas, a pagar a Fazenda Nacional a multa de metade do valor dos couros apprehendidos, e aos despachantes Salgaes \& Theulé, obrigo igualmente ao pagarnento it mesmu. Fazenda, da multa de metade do valor das garras de couro apprehendidas; e ordeno ao Escrivalo do processo que mande intimar às partes interessadas este meu julgamento, correndo o prazo para o recurso dentrode termo legal, da data da intimação; extrahindose copias authenticas desta decisáo e do termo de apprehenș̄o para serem submettidas a approvaçẵo da Thezouraria da provincia, nos termos do artigo duzentos oitenta e sete do citado regulamento de vinte dous de junho de mil oito centos trinta e seis; isto é, na parte que absolve e manda entregar os genetos, que haviam sido despachados e pagos os direitos nacionais = Alfandega e Meza do Consulado da Cidade do Rio Grande vinte oito de Abril de mil oitocentos cincoenta e seis = Sa Brito

Eu Abel Pires deOliveira, segundo Escripturario, servindo de Escrivăo que a presente fĩz extrahir, e val por mil conferida, subscripta eassignada, nesta Alfandega e Consulado do Rio Grande do Sul em 30 de abril de 1856 


$$
\text { II. }{ }^{\mathrm{mo}} \mathrm{e} \mathrm{Ex}{ }^{\mathrm{mo}} \mathrm{Sor}
$$

Accussando à recepção dos officios de V. Ex. ${ }^{3}$ datado de 6 , a 16 do corrente mes, em que dando sol uçắ à representação que enderezei a V. Ex. ${ }^{a}$ contra a aprehensăo e descarga da Polaca Hespanhola "Maria Lloweras", ed maneira porque tal apprehensão edescarga sefêz, sem aquellas attençðes que me parecișo devidas, por usos e costumes, para com o Agente Consular de Naçāo amiga, cumpre-me significar á V. Ex, ${ }^{2}$ que fico na esperança de que V. Ex. ${ }^{2}$ se đignará tomar em tempo opportuno em consideração pela favoravel decissão da qual debaixo do mais profundo respeito julgo deber instarperante V. Ex.

Aproveitando a occassizo tenho de renovar osprotestos deminha estima respecto e consideraç̃o a pessoa de V. Ex, ${ }^{a}$

Deos Guarde à V. Ex. ${ }^{\text {a }}$ - Vice-Consulado Hespanhol no Rio Grande it 27 de Maio de1856.

11. ${ }^{\mathrm{mo}} \mathrm{e}$ Ex. ${ }^{\mathrm{mo}}$ Sôr Consetheiro

Don Jeronimo Franc, ${ }^{\mathrm{co}}$ Coelho

Presidente daProwincia

Porto Alegre

Pablo Goycoechea

V. Consul

III. ${ }^{\mathrm{mo}} \mathrm{e}$ Ex. ${ }^{\mathrm{mo}} \mathrm{Set}$

No dia 23 de Dezembro do anno pp. ${ }^{\circ}$ pelas oito horas pouco mais ou menos da manhāa, fot espancado e ferido como consta do induso Corpo de delito, na Freguesia de $\mathrm{S}^{\text {ta }}$ Anna de Livramento em face de uma reuniao publíca, o Hespanhol José Zavaleta, honrado e pacifico, casado e com filhos. Este individuo por sua summa pobreza, nťo poude obter instauraçฐ̃o de processo, nem a Autoridade competente procedeu ex-officio ma forma das leis do pais.

Em semelhantes termos wou por meio deste apresentar 4 V. Ex. ${ }^{a}$ o referido Corpo de delicto seguro de que, V. Ex. ${ }^{a}$ se dignará por seu bem conhecido espirito de rectidalo e justiça mandar proceder conformo o direito. 
Aproveito a occassiao $\mathrm{p}_{\mathrm{a}}{ }^{\mathrm{a}}$ renovar à V. Ex ${ }^{\mathrm{a}}$ os protestos de minha estima e consideração. Deos Guarde à V. Ex. ${ }^{\mathrm{a}}$ muitos amnos. Vice Consulado d'Hespanha em Rio Grande 13 de março de 1857.

\author{
III. ${ }^{\mathrm{mo}} \mathrm{e}$ Ex. ${ }^{\mathrm{mo}}$ Ser Conselheiro \\ Don. Jeronimo Franc. ${ }^{c 0}$ Coelho \\ Digno Presidente da Província \\ Porto Alegre
}

Pablo de Goycoechea

Vice Consal

$$
\text { III. }{ }^{\mathrm{mo}} \mathrm{e} \mathrm{Ex}{ }^{\mathrm{mo}} \text { Senr. }
$$

Vice consulado de

S. M. Catholica

em Porto Alegre

Tendo no dia 9 doppassado sido recrutado na Cidade do Rio Grande para o serviço da Armada Imperial o subdito de S.M. Catholica Adolfo Fraga, que se acha forçado a servir a bordo do Vapor de Guerra -Apa, aopresente surto no porto désta Cidade, e não podendo sucitar-se duvida alguma acerca de sa Nacionalidade, como mostra o documento junto, e sendo incontestavel que sua qualidade de estrangeiro o garante de todo e qualquer serviço forçado; porisso o abaixo assignado Vice Consul da S. M. Catholica nésta Cidade roga a V. Ex. ${ }^{\text {cia }}$ se digne expedir as convinientes ordens para que o referido subdito seja posto em liberdade.

Aproveitando a oportunidade o abaixo assignado tem asubida hoora de significar a V. Ex ${ }^{\text {cia }}$ os sentimentos de maiot respeito e concideraçăo. DeosGuarde a

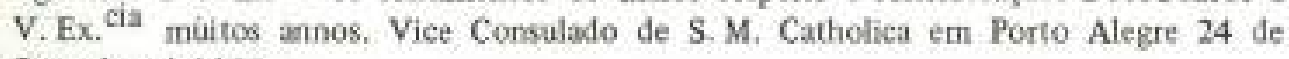
Seternbro de1859.

\author{
III. ${ }^{\text {mo }}$ Ex. ${ }^{\text {mo }}$ Señr Conselheiro \\ Joaquim Antî̄o Fry Leล̄o \\ Dignissimo Presidente désta Provincia.
}


Vice-Consulado de España

en

Estho Sör

Rio Grande del Sul

El abajo firmado Vice-Consul de S. M. C. tiene el honor de elevar à manos de V.E. el Exequatur por el que S. M. el Emperador ha tenido à bien reconocerlo en el earacter con que su Gobiemo lo ha investido a fin de que V. E. se sirva poner el cumplase à esa superior resolucion.

Adjunto à su vex un oficio de la Secretaria de Negocios Estrangeros de este Imperio que me ha sido transmitido par V.E.

El absjo firmado aprovecha esta ocasion para of recer à V. E. las seguridades de su mas distinguida consideracion y respecto.

Dios guarde à V. E. muchos años

Rio Grande del Sul febrero 21 de 1859

José Espalter y Duran

III. ${ }^{\text {mo }}$ Exmo. Sôr Consejero Angelo Muniz de Silva Ferraz

Presidente de la Provincia de S. ${ }^{\mathrm{n}}$ Pedro de R. ${ }^{\circ} \mathrm{G} .{ }^{\mathrm{e}}$ del Sul

Vice-Consulado de España

en Bage

Bagé, 26 de Abril de 1861.

ExT̄no Señor

Muy Señor mio: tengo ta honra de adjuntar d́ V. E. el Regiun Exequatur que me acredita en clase de Viceconsul de S. M. Catótica en esta ciudad y su Municipio, para que V.E. se digne mandarle poner el Cumplase y participarlo a las Autoridades Competentes de este lugar, afin de que estas me reconozcan en tal caracter.

Me consideraré afortunado Exîno Snt, ș al cumplir mis deberes oficiales. puedo conseguir que V. Excia forme la decidida conviccion, del vehemente deseo que me anima para la conservacion de las relaciones de amistad que felizmente existen entre el Gobierno de S. M. Imperial y el de S. M. Catolica. Tambien me serí grato sil logro hacerme perschalmente digno de todas las Autoridades en general, y la de V. Excia en particular. 
Sirvase V.E. aceptar Sñr Presidente las seguridades de mi distinguida contsideracion

El Viceconsul đe España

Ramon Galibem

Señor Presidente de la Provincia de S. ${ }^{\mathrm{n}}$ Pedro do

Rio Grande do Sul.

Vice Consulado

Pelotas julto 12.1861

de

España

en

Pelotas

El abajo firmado vice Consúl de sú Magesta Catolica, tiene el honor de dirijirse a su S. E. a el Sor Presidente acompañando el Exequatur que se ha servido el Goviemo de S. M. el Emperadór, consedérme para ejercér las funciones anerentes á micargo y espero de V. E, se digne poner ef "visto bueno" $y$ otro si ordenár á las. autoridades del districto, para que sea reconocido en tal Caractér. consideración

Aprovecho la ocación Sõr Presidente para saludárlo con la mas alta estimay

Que Dios guarde a V. E. " muchos afios

\section{Benito Maurell \\ Vice Consul}

Ao III. ${ }^{\mathrm{mo}}$ Ex. ${ }^{\mathrm{m}}{ }^{\mathrm{S}}$ Sỏr D. Jcaquin Antao Fernandes Leāo

Digrisimo Presidente de esta Provincia

Ilmo. Exmo. Snf

Tenho a honra de passar as mäos de V. Ex" o Exequatur que S. M. o Imperador do Brasil houve por bem conceder para que eu possa exercer interinamente o cargo de Vice Consul do Reino d'Hespanha nesta cidade. 

e consideração.

Prevaleço-me da ocasisăo para testemunhar a V. Ex ${ }^{3}$. o meu profundo respeito

Deos guarde a V. Ex ${ }^{a}$ Vice consulado de Hespanha no Rio Grande do Sul aos 11 de maio de 1861.

\author{
Ilmo. Exmo, Sñ̄ \\ Conselheiro Joaquim Antīo Fernandes Leão
}

Presidente desta Provincia

Jọ̄o Barbos: Ccelho

Vice Consul Interino

Pelotas julio 51862

$$
\text { III. }{ }^{\text {mo }} \text { y Ex. }{ }^{\text {mo }} \text { Señor }
$$

El abajo firmado Vice Consúl de Su Majestad Catolica ha tenido el honor de recibir el Oficio de $\mathrm{V} \mathrm{E}{ }^{2}{ }^{2}$ fha 18 de Junio $\mathrm{pp}$, el cual creo que por errór me viene dirijido como Vice Consull dela Republica Oriental del Uruguay y en contestacion me cumple decir á V. E. ${ }^{a}$ que el actual vice Consul de aquella Republica en esta Ciudad es el Sôr Dn. Manuel Montano

Aprovecho la oportunidad para reiterar a V, $\mathrm{E}^{\mathrm{a}}$ las seguridades de mi mas alta Consideracion y estima y que Dios guarde a VE muchos años

\title{
Benito Maurel \\ Vice Consul
}

III. mo y Ex, ${ }^{\text {mo }}$ Sör Conselheiro Fran ${ }^{\infty 0}$ de Assis Pereira Rocha muito Digno Presidente de esta Provincia 


$$
111 \mathrm{~m}^{\circ} \mathrm{Exm}^{\circ} \mathrm{Snr}^{+}
$$

Achando-se retido a bordo do Vapòr de Guerra Fluminense o subdito de S. M. Catholica Juan Raura, Offecial de Carpinteiro, tenho a hosira de appresentar a Va Ex ${ }^{\text {cia }}$ apapeleta que comprowa a sua Nacionalidade, e de rogar a $V^{i l} \mathrm{Ex}^{\text {cia }}$ de mandar pór em liberdade o dito Raura.

$O$ abaixo assignado tem a subida honra de signifiear a $\mathrm{V}^{\mathrm{a}} \mathrm{Ex} \mathrm{Ci}^{\mathrm{cia}}$ os senti. mentos de seo maior respeito e alta consideração. Deos Guarde a $V^{a}$ Ex cia. Vice Consulado de S. M. Catholica em Porto Alegre, 18 de janciro de 1862.

$111 \mathrm{~m}^{\circ}$ e $\mathrm{Exm}^{\circ} \mathrm{Sr}$ Dez ${ }^{\text {or }}$ Francisco de Assis Pereira da Rocha. Dignissimo Presidente desta província.

\author{
Jozé Fran ${ }^{\infty}$ dos Santos \\ Vice Consul
}

$$
11 m^{\circ} \text { e Exm }{ }^{\circ} \mathrm{Snr}
$$

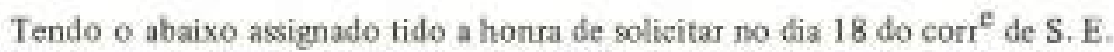
o Sni' Presidente desta Provincia a soltura do subdito de S. M. Catholica Juan Raura, Offecial de Carpinteiro da Ribeira que se acha retido abordo do Vapór de Guerra Fiuminense nāo tendo até hoje sido saptisfeita aminha reclamação talvez por que sobre este individuo peze alguã arguiçð̃o da Policia do paiz; porem constandome que o Vapör Fluminense segue sabado para o Rio Grande tenho a honra de dirigir-me a S.E. Snr' Presidente para rogar-the de mandar conservar aqui o dito Raura pois que aqui mesmo pretende provar perante S.E. apreceguiçajo que lhe faz a Policia de Pelotas onde elle está estabelecido com um estalleiro. $\mathrm{O}$ abaixo assignado de novo tem a subida honra de significar a S.E. os sentimentos de maior respeito e alta consideração.

Vice Consulado de S.M. Catholica em Porto Alegre 23 de janeiro de 1862.

$1 m^{\circ}$ e Exm ${ }^{\circ} \mathrm{Sr} \mathrm{Dez}$

Francisco de Assis Pereira da Rocha

Muito Digno Presidente desta Provincia. 
Vice consulado de Hespantia na cidade do Rio Grande, 25 de Janeiro de 1862

$$
n^{\mathrm{mo}} \text {. e Ex } \mathrm{Ex}^{\mathrm{mo}} \text {. Señ. }
$$

Tendo eu sido nomeado Vice Consul de Hespanha n'esta cidade em 14 de maio do anno findo, e tomando conta d'este Emprego em 25 de julho do mesmo anno, o meo antecessor Dr. José Espalter y Duran, negou-se a fazer-me entrega do archivo d'este Vice Consulado, do que fiz sciente o $\mathrm{Ex}^{\mathrm{mo}}$. Ministro de Hespanha na Còrte do Rio de Janeiro.

S. Ex ${ }^{\mathrm{cia}}$, ordenou-me que me dirigisse a essa Presidencia enviando-me para esse fim o incluso officio que tenho a Honta de enviar a VEx ${ }^{\mathrm{cia}}$; nâo o fiz immediatamente, como me era ordenado, porque o Señ. Espalter, achavase ausente, o que, participei ao $\mathrm{Ex}^{\mathrm{mo}}$. Srr.Ministro de Hespanha, que me ordenou em officio de 20 de Dezembro próximo passado, que désse cumprimento ás suas ordens e enviasse a V. Ex, cii o officio que Tinha remettido, o que nësta occasiăo cumpro, comunicando igualmente a VEx ${ }^{\text {cial }}$, que o referido meo antecessor ainda se acha ausente e són'esta cidade existe sua familia.

Tenho a honra de, por este motivo, apresentar a V. Ex ${ }^{\text {cia }}$, os protestos da

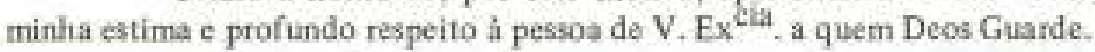

III $^{\text {mo }}$ e Ex ${ }^{\text {mo }}$. Señ. Desembargador Francisco de Assis Pereira Rocha D. Presidente d'esta Provincia.

O Vice Consul de Hespanha Zeferino A. Azambuja

Vice Consulado

Espanol

$$
{ }^{\mathrm{mo}} \mathrm{Ex}^{\mathrm{mo}}{ }^{\mathrm{Mn}} \mathrm{Su}
$$

E] Vice Consul de S. Magesttad Catolica tiene el honot de cumicar a VEx. ${ }^{3}$ que en consequencia de su estado deSalud de subito resolvio retirat-se para Europa por tres $\sigma$ cuatro meses y en esta $m^{m a}$ fecha deja encargado de este Vice-Consulado a su hijo Don Benito Maurell, a quien ha dado las instrucciones, y esclarecimientos recesarios para este fin. 
Despues de haver llevado este asunto a la alta consideracion de V. Ex ${ }^{a}$ aprovecha la oportunidad para tributar a V. $\mathrm{Ex}^{\mathrm{a}}$ su mas subida consideracion y respecto

Ciudad de Pelotas Mayo 15 de1864

$$
\begin{aligned}
& \text { D. }{ }^{5} \mathrm{G}^{e}{ }^{e} \text { a V.E m. ańos } \\
& \text { Benito Maurell }
\end{aligned}
$$

III. ${ }^{\text {mo }}$ Ex. ${ }^{\text {mo }} \mathrm{St} \mathrm{D}{ }^{\text {or João Marcellino de Souza Gonzaga }}$
D. Presidente de esta Prowincia

Vice Consulado

de

Expañล

en

Pelotas

Pelotas, 16 de Setiembre de 1864

$$
\mathrm{III}^{\mathrm{mo}} \text { y Ex. }{ }^{\mathrm{mo}} \text { Sentor }
$$

La Legacion de S. M. en Rio de Janeiro, aquien elevé por Copia la Comunicasion de V.Ex. ${ }^{2}$ de 13 de Julio ultimo, me dice en 16 de Agosto lo siguiente:

- Sentor Vicoconsul= La presidencia de esa Provincia no ha debido tener pessente al dictar su resolucion de 13 de Julio ultimo por lo que exigo a V. el Imperial Exequatur para ejercer interinamente funciones de ViceConsul dela nacion en esc' distrito lo que sobre el particulat prescribe el Articulo $5^{\circ}$ del Convenio Consular vigente entre los dos paises"

"Por ese articulo basta la designacion previa del titular para que sea $\mathbf{V}$. admitido a substituir-le y seria faltar .... estamente a la enunciada clausula sucitar del Govierno del Emperador ...... . requesito evidentemente innecesario.

"De esta comunicacion remitini ...... copia literal itla precitada Presidencia y me transmitirá V. la decicion, que sobre el particular adoptare"

"Reciba V. Señor Vice Consul las seguridades de mi perfecta consideracion"

Firmado J. Blanco det Valle

Lo que tengo la honra de transenbir á V.E ${ }^{\mathrm{a}}$ en cumplimiento dela precedente orden permitiendome, al proprio tiempo rogar a V. $\mathrm{E}^{\mathrm{a}}$ se sirva reconsiderar este asunto.

Dios Guarde î V.E ${ }^{a}$ muchos Añes

Benito Maurell hijo

Vice Consul Interino

III. ${ }^{\mathrm{m}}$ Ex ${ }^{\mathrm{m} \omega}$ Señor Presidente:

de esta Provincia 
[Anexo no doc, de 16.09,1864]

\section{Substituiçăo dos agentes Consulares}

Antigam. ${ }^{\text {te }} q^{\text {to }}{ }^{\text {to }}$ un consul ou VConsul estrangeiro tinha de retirar-se fazia se substituir pela forma determinada no $\mathrm{Av}$. de 10 de Juriho de 1847 . $\mathrm{O}$ agente consular nomeava uma pessoa para substitui-lo em seus impedim. ${ }^{\text {tos }}$ e recorria a Presidente da Provincia, que podia admittir provisorian. ${ }^{\text {te }}$ tal nomeeça marcando um praso indis: pensavel para apresentação do necessario Beneplácito Imp.al

Este beneplacito devia reçahir sobre nomeação dos Consules geraes, aos ques os agentes que tinhăo de ser substituidos deveriāo fazer suas porpostas

A convenção com a Hespanhar de 9 de Fevr. do anno passado, publicada pelo Deer. $\pi .^{\circ} 3.136$ de 31 de Julho, no art. ${ }^{\circ}{ }^{\circ}{ }^{\circ}$ alterou o Av. de 47 que regulava a materia estabelecendo que:

Em caso de impedimento, ausencia ou morte dos Consules e VConsules, os Chancelleres ou pessoas previam. te designadas pelo titular $\mathrm{p}^{\mathrm{a}}{ }^{\mathrm{a}}$ substituir-lo seršo admittidas a exercer interinam. ${ }^{\mathrm{fe}}$ as funç̧⿻es consulares, com aprovaçắo de authoridade local competente.

E p. ${ }^{r}$ tanto, dispensavel recorrer-se ao gowemo Imperial e ao Consulado Geral. Mas a Secretaria inadvertidam. ${ }^{\text {te }}$ fez o expediente na forma determinada pelo Av. de 1847. Parece pois que tem razão o VConsul, entretanto năo seria inconveniente consultar o Gov se Av. de 47 fica revogado pela convençָ̧̃o.

O Av. de 4 de junhe do Corret, anno, que vae annexo tracta de materia differente.

\section{Secret. ${ }^{\text {ia }}$ do gov, em P.Alegre $1 .^{\circ}$ Setembro 64} Augusto Cesar de Padua Fleury

Vice Consulado

Pelotas, 29 de Octubre de 1864

de

España

en

Pelotas

$$
\text { Ex. }{ }^{\text {mo }} \text { Sor Presidente }
$$

Tengo la honra de comunicar $厶$ V.E. ${ }^{a}$ que en esta fecha è tomado pocecion de este Vice Consulado Espanol a mi cargo, que durante mi aucencia fué desempeñado interinamente pot Beaito Maurell hijo. 
Aprovecho esta ocacion para reiterar i V.E $E^{\mathrm{a}}$ las seguridades de mi distinguida conside racion y estima

Q. D.G.M.A.

Benito Maurell

A Su Ex ${ }^{\mathrm{a}}$ el Sör D. ${ }^{\mathrm{T}}$ Jošo Marcellino

de Souza Gonzaga, Muy D. Presidente

de esta Provincta

Viee Consulado de Hespanha no Rio Grande do Sul, em 7 de Dezembro de 1864.

$$
\text { III. }{ }^{\mathrm{mo}} \mathrm{e} \mathrm{Ex}{ }^{\mathrm{mo}} \mathrm{s}{ }^{\mathrm{t}}
$$

O subdito hespanhol Francisco Iribarren representou-me que, no anno proximo passado, se ausentára de sua companhia o seo filho Joăo Eulalio Iribarrem, sabendo, porém, agora que elle se acha com praça, n'esta provincia no $4 .^{\circ}$ Regimento de Cavallaria de linhs.

Sendo tambem hespanthol o mesmo Jos̃o Eulatio, nāo podia, nem ser compellido ao serviço militar, nem à elle admittido como voluntario, por ser de menor idade, conforme consta d'este Vice Consulado e do competente certificado de nacionalidade passado em 15 d'Abril de 1861 .

Dirigindo-me, pois, a VExa tenho por fim rogar-the que se digne expedir ordem ao respectivo $\mathrm{S}$. ${ }^{\mathrm{T}}$ Commandante das Armas para ser escuso do serviço em que está o referido subdito hespanhol.

E por esta occasiano, tenho a satisfação de saudar a VExª com a major consideraçāo e respeitoza estima.

Deos Guarde a V.Ex ${ }^{\mathrm{a}}$

Ao III ${ }^{\mathrm{mo}}$ e Ex $\mathrm{x}^{\mathrm{mo}} \mathrm{S}^{\mathrm{t}} \mathrm{D}^{\mathrm{t}}$ Joāo

Matcellino de Souza Gonzaga

Presidente da Província 
N. 663

Vice Consulado

de

Españu

Pelotas Julio 31.1865 .

en

Pelotas

\section{Ex.mo Serihor}

He sido honrrado con el oficio VE. ${ }^{\text {a tha }} 21$ del cor, ${ }^{\text {te }}$, anunciandome, haberse recebido de la Presidencia de esta Provincia, para la cual fui nombrado V E. , por S. M. EI Emperadur (Q. D. G.) por carta Imperial de fha 7 del corr. ${ }^{\text {te }}$.

Agradesco a V.E ${ }^{\mathrm{a}}$ la participacion que se digna hacerme $\mathrm{y}$ aprovecho la ocacion para felicitar a V E. ${ }^{\mathrm{a}}$ por su nombramiento.

Soy de V.E. a Con toda Consideracion y estima.

E] Vice Consul de Espaคิa

Benito Maurell

III. ${ }^{\mathrm{mo}}$ Ex. ${ }^{\mathrm{mo}}$ Snr Visconde de

Boa Vista, muy digno Presidente

de esta Provincia.

\section{Rio Grande $1^{\circ}{ }^{\circ}$ 'Agosto de 1865}

Illmo e Ex ${ }^{\text {mo }}$ Sen!

Tenho a honra de accusar a recepçáo da Circular de VEx ${ }^{\mathrm{a}}$ de 21 de jutho proximamente findo na qual se Digna $\mathrm{VEx}^{\mathrm{a}}$ comunicarme haver no dia 20 d'aquelle mez tomado posse do Cargo de Presidente D'esta Provincia, para o qual Sua Magestade O-Imperador Houve por bem Nomear a VEx ${ }^{\mathrm{a}}$.

Agradecendo a VEx ${ }^{\mathrm{a}}$, tăo hourosa communicaçắo, prevaleço-me d'esta opportunidade para apresentar a VEx a protestos da minha particular estima e consideraçāo.

\section{Deos Guarde a VEx ${ }^{3}$.}

A.S. Ex $x^{a}$ o S $^{t}$. Visconde da Boa Vista

M. D. Presidente d'esta Provincia

Porto Alegre

O Vice Consul de Hespanhu

Zeferino Alves d'Azambuja 
VICECONSULADO DE ESPANA

en

RIO GRANDE DEL SUR

Rio Grande, 26 de Agosto de 1865

$$
\text { III. }{ }^{\mathrm{mo}} \mathrm{e} \mathrm{Ex}^{\mathrm{m}} \mathrm{s}_{\mathrm{S}} \text { ? }^{\mathrm{T}}
$$

Tenho a honrs de participar a V.Exa que, tendo urgencia de retirar-me temporariamente d'esta cidade, deixo, em conformidade do dispôsto no Art. ${ }^{\circ} 5 .^{\circ}$ da Convenção Consular entre of Brasil e a Hespanha, promulgada por Decreto n. ${ }^{\circ} 3.136$ de 31 de Julho de 1863 , so S. ${ }^{\mathrm{r}}$ Manoel Alves Pires de Azambuja, negociante residente n'esta cidade, encarregado da gerencía d'este Vice Consulado, pedindo a V.Exª se digne approvar esta minia nomeaçâo.

Reitéro a V.Ex., ${ }^{a}$ os protestos da minha consideraçẵo e profundo respeito.

$$
\text { Deos G. }{ }^{\text {de }} \text { a V.Ex. }
$$

A S. Exa o S. ' Visconde da Boa Vista

Presidente d'esta Provincia

O Vice Consul de Hespantha

Zeferino A d'Azambuja

Rio Grande 26 de Setembro de 1865

III. ${ }^{\mathrm{mo}} \mathrm{e} \mathrm{Ex} .{ }^{\mathrm{mo}} \mathrm{Sen}^{\mathrm{s}}$

Tenho a honra de participar a VEx ${ }^{2}$ que, no dia 19 do corrente reasumi as funofióes do Cargo de Vice Consul de Hespanha n'esta Cidade.

Reitero a VEx. ${ }^{a}$ os protestos de minha estima o profundo respeito.

Decos Guarde a VEx ${ }^{2}$

III $^{\mathrm{mo}}$ e $\mathrm{EX}^{\mathrm{mo}}$ Sen $^{\mathrm{r}}$ Visconde da Boa Vista,

o Vice Consul de Hespanha

Zeferino Al Azambuja

Presidente d'esta Provincia 
$\mathrm{N}^{\circ}{ }^{\circ} 57519 / 12$

\section{Viee Consulado de Magestade Catholies em}

Porto Alegre 9 de Dezembro de 1865

$$
111 \mathrm{~m}^{\circ} \mathrm{Exm}^{\circ} \mathrm{Snt}
$$

O abaixo ussignado Vice Consul de S. M. C. tem a honra de dirigirse a S. Ex. ${ }^{\text {cil }}$ o Snr Presidente da Proviscia para fazer the sciente, que o Subdito de S.M.C. Adolfo Fraga fot recrutado para o serviço da G. Nacional em destacam ${ }^{\text {to }}$ do esquadräo ou Cỏrpo do Commando do Maỹor Primordio Centeno de Azambuja, e sendo incontestavel que a sua qualidade de estrangeiro como prova pelo documento junto, o garante de todo e qualquer serviço forçado, por isso o abaixo assignado roga a V. Ex ${ }^{\mathrm{cia}}$ se digne expedir as convenientes ordens para que o referido subdito seja pósto em liberdade.

Aproveita a oportunidade o abaixo assignado para ter a honra de sferificar a V. Ex ${ }^{\text {cia }}$ os sentimentos de maior respeito e alta consideraçĩo e a quem Deos Guarde:

Illm ${ }^{0}$ e Exm ${ }^{0} \mathrm{Sr}$. General Visconde da Boa Vista, Dignissimo Prezidente desta Provincia.

$$
\begin{aligned}
& \text { José Frane. }{ }^{\text {Co }} \text { dos Santos } \\
& \text { Vice Consul. }
\end{aligned}
$$

Río Grande, 17 de Fevereiro de 1866

$$
\text { HII }^{\text {mo }} \mathrm{ex}{ }^{\text {mo }} \text { Sen. }{ }^{\mathrm{I}}
$$

Tenho a honira de communicar a V Ex. ${ }^{a}$ que, o subdito hespanhol Nicolảo Rocha, acaba de me representat, que seo filho Josk Maris Rocha, de idade de 21 annos, fóra compellido a servir na $3 .^{a}$ companhia avulsa de Guardas Nacionses da cidade de Jaguarão, e sendo o refe rido Josk Maria Rocha, subdito de S.M.C. eonforme o disposto no $\$ 2 .{ }^{\circ}$ do Art. $10^{0}$ da Constituição Hespanhola, solicito de V. Ex. ${ }^{\mathrm{a}}$ a expedição de suas ordens, a fim de ser eliminado do se rviço o mencionado José Maria Rocha.

Renóvo a V Exa os protestos de meo profundo respeito, $e$ estima.

Decos Guarde a V Ex.

llimo e Ex. ${ }^{\text {mo }}$ Sen ${ }^{\mathrm{T}}$ Visconde da Boa Vista

D. Presidente d'esta Provincia. 


$$
\text { III. }{ }^{\mathrm{mo}} \mathrm{e} \mathrm{Ex}{ }^{\mathrm{mo}} \mathrm{Sen}^{\mathrm{T}}
$$

Tenho a honra de me dirigir a V. Ex. ${ }^{a}$ communicando-lhe que o cidadilo hespanhol Isidro Bittencourt, me representou que seo filho legitimo Candido Domingos de Bittencourt, foi contra sua vontade obrigado ao serviço do Imperio no Contingente de Cavallaria de $\mathrm{G} .{ }^{\mathrm{S}} \mathrm{N}{ }^{5}$ da cidade de Jaguar 30 .

Gosando pelo \& $2{ }^{\circ}$ do Art. $^{\circ} 1 .^{\circ}$ da Constituição Hespanhola, os filhos de hespanhóes, os fóros e regalias da nacionalidade de seos pais; vou rogar a V. Ex. ${ }^{2}$, à vista do documento que tenho a honra de enviar junto a este, as necessarias ordens a fim de que o dito Candido Domingos de Bittencourt, seja excluido do serviço em que se acha.

Deos Guarde a V. Ex.

III. ${ }^{\mathrm{mo}} \mathrm{e}$ Ex. ${ }^{\mathrm{mo}} \mathrm{Sen}, \mathrm{D},{ }^{\mathrm{t}}$ Antonio Augusto Pereira da Cunha. Vice-Presidente d'esta Provincia

\author{
Porto Alegre. \\ Zeferino Ad' Az:ambuja \\ Vice Consul
}

[Anexo do documento de 25 de Abril de 1866]

\author{
P. Nicoláo Maria Berardy \\ Presbytero Secular do Habito de \\ S. ${ }^{\text {n }}$ Pedro Vigario Encarregado da Igreja \\ Matris desta cidade de Jag. ${ }^{\text {m }}$
}

Certifico, que pot me ter sido pedido que revendo o livro primeiro que serve para nelle se lançat os Assentos de Baptismo dos justificados por esta Commarca oqual se acha em exercicio nelle a folhas quarenta e oito á quarenta e oito verso encontrei oseguinte $=\hat{\text { Los }}$ trinta dias domes de Novemboo de mil oitocentos quarenta e seis, nesta Igreja Matriz do Divino Espirito Santo da Villa de Jaguarajo Baptisou solemnemente epós os Sintos Ollios o Reverendo Vigario Jodo Themudo Cabral Dinis ao imnocente Candido Domirgos de Bittencourt, branco, natural desta vilta, fitho legitimo de Isidro Bittencourt natural das Ithas Canarias Hespanha, e de Leisa Frabrica, natural do Estado Otiental: netto patemo de Manoel Bittencourt e Luisa Canora naturais das Bhas Canarias, Matemo de Paschoal 
Fabrica e Maria Sannes ambos naturais de Inglaterra, o inocente Candido nasceo no Dia tres de Outubro do Corrente Anno; forāo seus padrinhos Francisco Antonio Outeiro e Filisbina Fabtica: Epara constar lavrei opresente termo em virtude da Sentença do Illustrissimo \& Reverendissimo Senhor Vigario da Vara desta Commarca Joảo José da Potciuncula proferida nos autos de justificaçlo de Baptismo afolhas a scis veręo em dacta de vinte oito de Marco deste presente Anno mil oitocentos secenta e seis, de Candido Domingos de Bittencoutt requerida por sua máe Luisa Fabrica Eu João Antunes de Salles escrivăo de Audictorio Eecleziastico que o escrevi. Padre Nicolśo Maria Berardi = Enada mais se continha em o dito assen to que bem fielmente mandei extrahir apresente Certidão por me ter sido pedida do proprio livro ao qual me reporto, que somente vai por mim assigrada. Ciclade de Jaguardo quatro dias do mes de Abril deste presente anno mil oitocentos secentue seis.

\section{Padre Nicolao Maria Berardi Vigario Interino}

Reconheço a assignatura supra

Jaguaräo 4 de abril de 1866

\section{Joåo da Silva Vieira Braga}

Nosotros abajo firmados subditos de su M. C. a falta de vice -consul en esta Ciudad certificamos verdadera la firma del Escrivão Publico que antecede, D. Juan da Silva Vieira Braga. En fé de lo cual firmamos en la Ciudad de laguaron à 5 de Abril de 1866

\section{Pascual Mourino}

Nicolao Rocha

Rio Grande, 22 de julho de 1866

III. ${ }^{\text {no }} \mathrm{e} \mathrm{Ex} .{ }^{\mathrm{mo}} \mathrm{Sér}$.

Em 25 d'Abril tive a honra de me dirigir a VEx. ${ }^{3}$ pedindo a expediçióo de suas ordens a fim de ser escuso do serviço em que se achava no Contingente de Cavallaria do Guardas Nacionaes da cidade de Jaguarśo Candido Domingos de Bitencourt, fillio do eidadîo hespanhol Isidro Bitencourt e VEx. pot seo officio de 8 de Majo, dignou-se communicar-me que, havia expedido suas respeitaveis ordens para tal fim, o que muito agradepo a VEx.

Acaba, porem, o referido Isidro Bitencourt de dirigir-me uma representacido, dizendo-me que seo fillo ainda continua a estar em amias, dizendo-lhe a autoridade 
militar d'aquella cidade, năo ter de VEx. ${ }^{\text {a }}$ recebido ordem alguma a respeito; por tanto solicito de VEx. ${ }^{a}$ que se digne ordenar a quem competir o cumprimento do que VEx. ${ }^{a}$ já houve por bem determinar.

\section{Deos Guarde a VEx."}

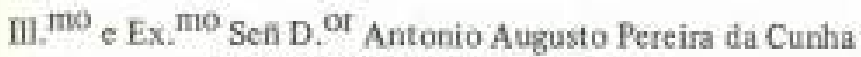

D. Vice Presidente da Provincia

Porto Alegre

O Vice Consul de Hespanha,

Zeferino Ad'Azambuja

Rio Grande, 24 de jutho de 1866.

III. ${ }^{\text {mo }}$ e Ex. ${ }^{\text {mo }}$ Señ.

Os documentos que tenho a honra de enviar a VEx ${ }^{\mathrm{a}}$, prováo,, $01^{\circ}$ que Pedro Bello, é cidadáo hespanhol, e o $2 .^{\circ}$ que Francisco de Paula Bello, $e$ seo filtho legitimo, e como este fósse coagido a servir na Companhia de Artilharia de Guardas Nacionaes da Cidade de Jaguarăo, requeréo-me o primeiro a isençăo do serviço em que se acha seo filho; por tanto vou solicitar de VEx. ${ }^{a}$ a expedição de suas ordens a fim de que dito Francisco de Paula Bello, seja escusso do serviço militar em que se actsa.

Aproveito este ensejo para reiterar a VEx. es protestos do meo profundo respeito e consideração.

Deos Guarde a VEx. ${ }^{\text {a }}$

11. ${ }^{\text {mo }}$ e Ex. ${ }^{\text {mo }}$ Señ. D. ${ }^{\text {or }}$ Antonio Augusto Per. ${ }^{a}$ da Cunha

D. Vice - Presidente ds Provincia

Porto Alegre

o Vice Consul de Hespanha, 
Rio Grande, 16 de Outubro de 1866.

$$
\text { III. }{ }^{\mathrm{mo}} \mathrm{e} \mathrm{Ex}^{\mathrm{mo}} \mathrm{Señ.}
$$

Em 25 d'Abril e 22 de julho do corrente anno, tive a bonra de me dirigir a V. Ex. ${ }^{a}$ solicitando a dizpensa do servico em que se achava no Contigente de Cavallaria de Guardas Nacionais da Cidade de Jaguarāo Candido Domingos de Bitencourt, filho do hespanhol Isjdro de Bitencourt, e em resposta Y. Ex. ${ }^{2}$ dignou-se em Officio datado de 29 de Julho $\overline{\mathrm{p}} \overline{\mathrm{p}}$, dizer-me que n'aquella data teiterava a ordem ao Señ. Commandante das Armas para mandar escussr do serviço dito Candido Dominigos de Bitencourt.

Pela inclusa petiçẫo que do pai do dito Bitencourt, acabo de seceber, verá $\mathrm{V} \mathrm{Ex}{ }^{a}$ que ainda continù a ser chamado à serviço; portanto wou respeitosamente pedir a $V E^{a}$ seja servido expedir suas terminantes ordens a fim de, por uma vez deixal-o em paz.

Aproveito esta occasialo para reiterar a V Exa ${ }^{a}$ os meos protestos de estima, consideraçāo $\mathrm{e}$ profundo respeito.

\section{Deos Guarde a V Ex ${ }^{\mathrm{a}}$.}

$\mathrm{III}^{\mathrm{mo}}$ e $\mathrm{Ex}^{\mathrm{mo}}$.S. ${ }^{\mathrm{I}}$ D. ${ }^{\mathrm{I}}$ Antonio Augusto

Peteira da Cunha,

Vice Presidente d'esta Prov.

o Vice Consul de Hespanha, Zeferino Ad'Azambuja

Snc. Vice $=$ Consul de S.M.C.

Isidro Betancour subdito Español viene ante Ud. inplorar la proteceion que le és debida para un hijo del suplicante de nombre Candido Betencour, de quien yá Ud tiene conocimiento. Potintervencion de Ud a sido este absuelto hace meses del servicio de la G.N. de Jaguarāo, a donde el suplicante seside, pero nuevamente intenta el Commandante Superior de dicha G.N. forza = lo al servicio de que ya establa dispensado, desatendiendo las ordenes que anteriormente habia recebido de S. Ex $x^{3}$ el Snt Presidente 
Como el suplicante és pobre $\mathrm{y}$ cargado de huna numerosa familia lo arruina y atraza la perseguición quel suplicante está sufriendo en la persona de su hijo,

En este cazo, ruego a Ud se digne, pedir nuevamente a quien de derecho sea la vaja del servicio para Candido Betancour

\title{
E. Y.
}

Aruego de Isidro Betancoat

Rio Grande, 26 de Novembro de 1866.

$$
\text { III. mo e Ex. mo Señ. }
$$

Tenho a honra de enviar a V Ex. a a inclusa certidẫo đe Baptismo pela qual şe reconhece que Zacharias Salcedo é filho de Ramon Salcedo, subdito de S. M. C., e como tal gosa das prerogativas de ciđadão Hespanhol; e como fösse chamado a serviço para o $2 .^{\circ}$ Batalhāo de Infantaria de Guardas Nacionaes, wou solieitar de V. Ex. ${ }^{a}$ a expediçāo de sans ordens a fim de ser o referido Zacharias Salcedo, dispensado do se rviço para que foi chamado,

\author{
Decos Guarde a V. Ex." \\ III. ${ }^{\text {mo }}$ e Ex. ${ }^{\text {mo }}$ Señ D. ${ }^{\text {or }}$ Antonio Augusto Per. ${ }^{\mathrm{a}}$ da Cunha \\ D. Vice Presidente d'esta Provincia \\ o Vice Consul \\ Zefirino A d'Azambuja
}

$\operatorname{IIIm}^{\circ} \operatorname{Exm}^{\circ}$ Señr :

Tenho a honra de levar ao conheçim ${ }^{\text {to }}$ de VE. que S M O Imperadot por çua Imperial graça me concodeu $O$ Imperial Exequatur junto, para poder funçionar no Cargo de Vice Consul da Hespanha nesta Villa por nomeaçăo de S E. o Sent Ministro de S M C. no Rio de Janeiro; como năo me he possivel funcionar cem odevido reconheçim ${ }^{\text {to }}$ de 
V E. rogo por tanto a V E. ce cirva Ordenar que ce lhe de o devido andamento que he de costume.

Deos Guarde a V E muitos Annos. Uruguayanna

8 de junho d'1866

Antonio Monjardim

Illm $^{\circ}$ Exm $^{\circ}$ Señr Prezid ${ }^{e}$ da Prov ${ }^{\mathrm{a}}$ do $\mathrm{R}^{\circ}$ Grande do Sul

Vice-Consulado de España

en

Bagé

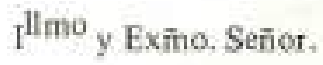

Tengo la hona de elevar al conocimiento de V.E., que hallandose el subdito de S.M.C. Josf Mederos nacido en esta Provincia e hijo de padres españoles entolado en la Matricula de este Viceconsulado, $y$ sirviendo militam ${ }^{\text {te }}$ contra su voluntad y á la fuerza en el cuerpo N. ${ }^{0} 32$ al mando del Sirr. Ten. ${ }^{t e}$ Coronel D. Vasco Jozé Farinha cuyo cuerpo se halla destacado inmediato a esta ciudad, y habiendo dicho José Mederos presentado su carta de nacionalidad al referido Sñr. Teniente Coronel solicitando la sol tura, este Snf, ha tenido a bien negarsela.

Como tengo orden de mi Superior para espedir cartas de nacionalidad espanola if todos los hijos de subditos de S.M.C. nacidos en este Imperio que me las soliciten, reconociendolos como á tales y haciendo que gucen de las miamas inmunidades que como $f$ estrangeros nos concedea las Leyes, y Tratados que existen entre el gobiemo de S.M.I. y el de S.M.C., con el mas profundo respeto ruego S V.E. se digne mandat espedir las precisas ordenes para que el mencionado. José Mederos sea suel to del servicio militar, y pueda pacificam, te retirarse á su morada.

Esperando de la benevola bondad y justicia de V.E., la Concesion que tengo la honra de pedirle, me anticipo en dar i V.E. los mas espresivos agradecimientos. Con este motivo Snf. Presidente, cabeme el honor y el placer de ofrecer AV.E. las seguridades de mi mas distinguida consideracion.

Dios guarde 1 V.E.

Bagé $10^{\circ}$ de Agosto de 1866.

III. ${ }^{\text {mo }}$ y Exmô. Snî. Presidente de la Provincia de Rio Grande del Sur.

III. ${ }^{\text {mo }}$ y Exmo Señot.

El Vicoconsul de España 
Vice Consulado de Esparia

en

Bagé

$$
\text { III }^{\text {mo }} \text { y Exmo Señor }
$$

Tengo el honor de elevar al conocimiento de V.E, haber recibido et oficio que con fecha 22 de Enero ultimo se dignó V.E. dirigirme, comunieandome que en aquel dia V.E. tomó posesion y prestó juramento del cargo de Presidente de esta Provincia por Carta Imperial de S.M. El Emperador, de fecha 27 de Dieiembro ppdo.

Muy grato me ha sido Exmo. Senot, el recibir la participacion con que V.E. se ha dignado honrarme, $y$ al felicitar $\&$ V.E. por tan alto $y$ distinguido cargo, me cabe el honor de manifestar á V.E. mis favorables deseos, de que la Divina Providencia se digne dispensar a V.E. toda clase de aciertos y felicidades en su dificil administracion.

Con este motivo Sar. Presidente, vengo a V E. se digne aceptar las seguridades de mi mas distinguida consideracion.

Dios Guarde if V.E muchos anos.

Bagé 18 de Febrero de 1867.

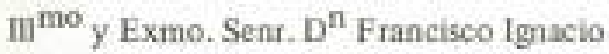

Marcondo Homem de Mello

Dignis $^{\text {mo }}$ Presidente de la Provincia de Rio

Grande del Sud

III ${ }^{\mathrm{mo}}$ y Exmo Senor

El Vice-Consul de Espana

Galibern

Vice Consulado

Pelotas Febreto 2, 1867, de

España.

en

Pelotas

Ex ${ }^{\text {mo }}$ Señor Presidente:

He sido honrado con ol officio de $\mathrm{VE}^{\mathrm{a}}$ sua 22 de Enero $\mathrm{pp}^{\mathrm{do}}$, comunicandome haber tomado pocecion de la Presidencia de esta Provincia, para la cual fuć $V^{2} E^{2}$ nombrado por carta Imperial de 27 de Diciembre altimo. 
Me cabe agradecer a V E esa participacion al propio tiempo, que folicitirlo por la al ta Comflanza, que merecio $\mathrm{V} \mathrm{E}^{\mathrm{a}}$ del Govlemo Imperial.

Me congratulo con el nombramiento de $\mathrm{V} \mathrm{E}^{\mathrm{a}}$ porque estoy seguro, que, mis reçamaciones, siempre fundadas en derecho, encontrarón en V E ${ }^{\mathrm{a}}$ toda justicia e imparcialidad.

A provecho esta ocacion para presentít a V $E^{a}$ las seguridades de mi perfecta consideracion y estima.

\section{Benito Maurell}

A Su Ex ${ }^{a}$ El Señor D ${ }^{\text {or }}$ Francisco Ignacio Marcondes Homern de Mello mui digno Presidente de esta Provincia

Vice Consulado

Pelotas Febrero 24. 1867

de

España

en

Pelotas

$$
\text { Ex }{ }^{\text {mo }} \text { Señor Presidente: }
$$

Pongo en conocimiento de $\mathrm{VE}^{\mathrm{a}}$ que teniendo que ausentárme de esta Provincia por algun tiempo, queda desde esta fectia, encargado de este Vice Consulado de España el Señor Vice Consul de la Republica Oriental del Uruguay, Don Benito Maurell y Lamas deración y estima.

Aprovecho la oportunidad de renovar a $\mathrm{VE}^{\mathrm{a}}$ los protestos de mi consiA Su Ex ${ }^{\text {a }}$ El Señot Doctor Don Francisco Ignacio Marcondes Homem de Mello M. D. Presidente de esta Provincia 


$$
111 \mathrm{~m}^{\circ} \text { e } \mathrm{Exm}^{\circ} \mathrm{Snr} .
$$

O abaixo assignado Vice Consul de S. M. Catholica nesta Cidade tem a honira de dirigir-se a Sua Ex ${ }^{\text {cia }}$ o Snr Vice Presidente da Provincia para fazer-the sciente, que o subdito de S. M. Catholica Andres Passos representou a este Vice Consulado de se achar preso na Cadeia desta Cidade desde o dia 22 do passado, sem calpa formada e sómente por suspeitas; este procedimento alem de injusto ó vexatorio, e por isso sollicita o abaixo assigrado de Sua Ex ${ }^{\text {cia }}$ o Snr Vice Presidente suas terminantes ordens para ser posto em liberdade aquelle subdito de S. M. Catholica.

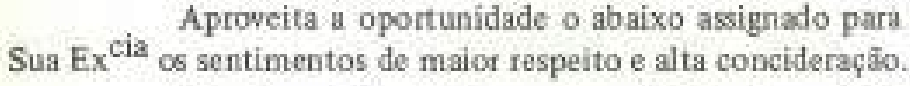

Vice Consulado de Hespanha em Porto Alegre 3 de Janeiro de 1867.

Ilim $^{0}$ e Exm ${ }^{\circ}$ Sr D ${ }^{\text {or }}$ Antonio Augusto Per ${ }^{a}$ da Cunha Dign $^{\text {mo }}$ Vice Presidente da Prowincia

Jozé Fran ${ }^{\mathrm{CO}}$ dos Santos Vice Consal

$$
\mathrm{II}^{\mathrm{mo}} \text { Exm }^{\circ} \text { Set }
$$

$\mathrm{O}$ abaixo assignado Vice Consul de S.M. Catholica nesta Cidade tem a honra de pồ na prezença de S. Ex cia o Snt. D. ${ }^{\text {or }}$ Franciseo Ignacio Marcondes Homem de Mello, Presidente desta Provincia que acaba de chegar so seu conhecimento, de ter sido assacinado no Municipio de Caçapava, districto de Santa Anna da Boa Vista, o subdito Hespanhol Caetano Joaquim Murchuack, e que o Subdelegado de Policia d'aquelle Districte, Marcelino Domellas de Oliveira tomou conta dos berı que consistiăo em Fasendas seccos e molhados, e que pagou dividas do infeliz assacinado a seu bel prazer-

Este facto, Exm ${ }^{\circ} \mathrm{Snr}_{4}$ é todo elle criminoso por ser contra as Leys do paiz e contra os tractados que existem entre o Governo de S.M. Imperador do Brasil S.M. a Rainha de Hespanha; $e$ o abaixo assignado pondo-o na prezença de V.E., espera que seja reponsabilizado aquelle funcionario por todos os prejuizos percas e damnos cauzados of herança, e para que senăo reproduzî̃o Crimes de igual natureza. 
Aproveitundo esta oportunidade of abaixo assignado term a subida hontra de significar a V.E. os sentimentos de maior respeito e alta concideraçso. Vice Consulado de Hespanha en Porto Alegre 3 de jullio de 1867.

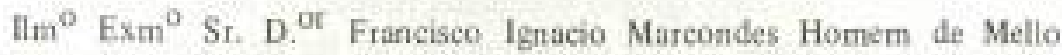
Presidente da Provincta

\author{
Joze Fran. ${ }^{\infty 0}$ dos Santos \\ Vice Consul
}

Vice Consulado de Hespanha em

Porto Alegre 26 de Janeiro de 1867

$$
111 \mathrm{~m}^{\circ} \mathrm{e} \mathrm{Exm}^{\circ} \mathrm{S} x
$$

O abaixo assignado Vice Consul de S. M. Catholica nesta cidade tem a honra de acuzar a recepsio do officio que em 22 do corrente the dirigio o Exsm ${ }^{\circ}$ Sur $D^{\text {or }}$ Francisco lgnacio Marcondes Homem de Mello, participando-the, que por Carta Imperial de 27 de Dezembro ultimo se Dignou S.M. o Imperador nomealo Presidente desia Provincia e que havia tomado posse n'aquella dacta.

Apreciando devidamente afineza com que V. E, acaba de tractar o Vice Consul de Hespanha elle com os subditos de S.M. Catholica se associảo no justo contentamento a populaçato desta bela Provincia pela acertada escolla que de V. E. for S. M. o Imperador do Brasil e augeurando so Governo de V. E. lodas as prosperidades que promettem a alta entelligencia e acry zolado patriotisrno do seu primeiro Magistrado.

Prevaleço-me desta opportunidade para ter a subida honra de signtificar a V. E. o maicor respeito e alta concideraçĩo aquem Deos Guarde

Illm ${ }^{\circ}$ e Exm ${ }^{\circ} \mathrm{Sr}^{\circ}{ }^{\circ}$ Francisco Ignacio Marcondes Homem de Mello, Muito Digno Presidente da Proveia 


$$
\lim ^{\circ} \text { e Exm }{ }^{\circ} \mathrm{Srr}
$$

O abaixo assignado Vice Consul đe S.M. Catholica nesta Cidade tem a honra đe pôr na

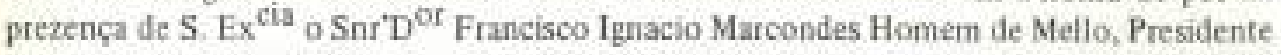
desta Prowincia que acaba de chegar ao seu conhecimento, de ter sido assacinado no Municipio de Caçapava, districto de Santa Anna da Boa Vista, o subdito Hespanhol Caetano Joaquim Murchuack, e que o subdelegado de Policia d'aquelle Districto, Marcelino Domellas de Otiveira tomou conta dos bens, que consistiajo $\mathrm{cm}$ Fasendas seccos e mothados, e que pagou dividas do infeliz assacinado a seu bel prazer?

Este facto, Exm ${ }^{0}$ Snr', é todo elle criminoso por ser contra as Leys do paiz e contra os tractados que existem entre o Governo de S.M. Imperador do Brasil e. S.M. a Rainha de Hespanha; $e$ o abaixo assignado pondo-o na prezença de V.E, espera que seja responsabilizado aquelle funcionario por todos os prejuizos percas e damnos cauzados á herança, e pars que senaio reproduzio crimes de igual natureza.

Aproweitando esta oportunidade o abaixo assignado tem a subida honra de signifscar a V.E. os sentimentos de maior respeito e al ta concideraçäo. Vice Consulado de Hespanha em Porto Alegre 3 de Julho de 1867.

$\mathrm{IIm}^{\circ}$ e Exm ${ }^{\circ}$ Sr D $\mathrm{D}^{\mathrm{Ot}}$ Francisco Ignacio Marcondes Homem de Mello.

Presidente da Provincia

\author{
Jozé Fran ${ }^{\mathrm{CO}}$ dos Santos \\ Vice-Consul
}

[Anexo $n^{\circ} 1$ ao documento de 03 de Julho de 1867 ]

$$
\text { III }{ }^{\text {mo }} e \mathrm{Ex}^{\mathrm{mo}} \text { Señr. }
$$

Satisfasendo o que VEx ${ }^{\mathrm{a}}$ de mim exige em officio, sob $n{ }^{\circ} 21$, datado de 3 do oorrente, remetto 5 VEx ${ }^{\mathrm{a}}$ os originais officios do Juiz Municipal Supplente, e Subdelegado de Policia da Fregueșa de Sant'Anna da Boa Vista, telativos a arrecadaçấo dos bens deixados pelo subdito Hespanhol Caetano Joaquim Murchuack, que foi assassinado no districto da mencionada Freguesia.

Dos referidos officios verá VEx ${ }^{\mathrm{a}}$, que o $2 .^{\circ}$ supplente d'aquelle subdelegado, Marcellino Dornellas de Oliveira, errou, é verdade, entregando por algum tempo á um dos credores o espolio d'aquelle finado; todaria năo consta que tivesse pago dividas, como se diz. 
Autorizado pelo respectivo Viee Consal, o cidadāo Julio Alvares dos Santos Pessoa trata de receber pelo Juiso competente o referido espolio.

$$
\begin{aligned}
& \text { Deos Guarde a VEx }{ }^{\text {I }} \quad \text { Villa de Caçapava } 24 \text { de jultho de } 1867 . \\
& \text { III }{ }^{\text {mo }} \text { e Ex }{ }^{\text {mo }} \text { Señr Presidente da Provincia. }
\end{aligned}
$$

O Juiz de Direito

José de Araujo Brusque

[Anexo n. ${ }^{\circ} 2$ ao documento de 03 de fullo de 1867]

$$
\text { III }{ }^{\mathrm{m} \infty} \mathrm{Sr} \text {, }
$$

Em resposta ao officio de $\mathrm{VS}^{\mathrm{a}}$ datado de 15 do corrente, em que exige, the informe circunstanciadamente sobre a atrecadação dos beas do subdito Hespanhól Caetano Josquim Murchuack, que fol assassinado no Districto de S. Anna da Boa Vista,

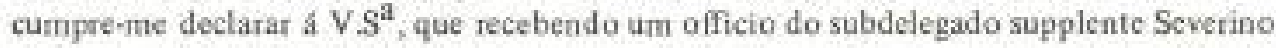
Domelles Doliveira, participando-me que tinha arrecadado, e estava em seo poder o espolio do $\mathrm{m}^{\mathrm{mo}}$. firtado, dei as providencias constantes do meo officio por copia sob $\mathrm{n}{ }^{\circ} 1$, e em consequencia terũo relacionados os bens, que constituem o dito espolio, e legalmente depositados, come consta de outro officio do respectivo subdelegado por copia sob $n .^{\circ} 2$, e dei de tudo isto posto ao respectivo Vice Consul de Hespanha em Porto Alegre, que me respondeo, como verá Vossa $\mathrm{S}^{a}$ do officio por copia $\mathrm{n}^{\circ} 3$, que autorizou ao Negociante Julio Alvares dos Santos Pessóa para tomar conta de tudo quanto pertencia ao mesmo finado.

\section{Deos Guarde a V.S}

Caçapava 20 de julho de 1867

III ${ }^{\mathrm{m} \infty} \mathrm{Sr}$. D $\mathrm{D}^{\mathrm{ot}}$ José d'Araujo Brusque.

Juiz de Direito desta Comarca. 
[Anexo $n^{\circ} 3$ do decumento de 03 deJulho de 1867]

Copia n: ${ }^{\circ}$.

lllustrissimo Senhor $=$ Em respesta ao seo officio datado de vinte e seis do corrente, cumpre-me dizer the, que sendo o finado Caetano Joaquim Murchuack, subdito do Govemo Hespanhól, com quem o Brasil estipulou uma Converiçāo Consular, compete ao respectivo Consuil a arrecadaçs̄o de seus bens; e por tinto nšo podia Vossa Senhoria ter outro procedimento, se nấo o de fazer relacionar seus bens em presença de duas testemunhas, e depositalos, dando-me disso parte; mas como se achão os ditos bens em seo poder, convem, que Vossa Senhoria os mande relacionar, e depositar em poder de pessóa iđonea até a intervençấo do respectivo Consill, a quem nesta data vou officialmente dirigir-me ao Consul da Hespanha para os fins convenientes; dignande-se Vossa Senhoria para semelhante fim enviar-me uma copia authentica da mesma relação = Deos Guarde á Vossa Senhoria Caçapava dez de Maio de mil oito contos e secenta e sete.= Illustrissimo Senhor Subdelegado de Policia do Districto de Sunta Anna da Bòa Vista, = Francisco Manoel Gomes, Juiz Municipal e d'Orfãos substituto.=

\section{Estí conforme o Original}

O Esct ${ }^{\mathrm{m}}$, Miguel José de Campos.

[nexo $n^{\circ} 4$ ao documento de 3 de Julho de 1867 ]

$\operatorname{Copia~}^{\circ} 2$

Illustrissimo senbor $=$ Respondendo ao officio de Vossa senhoria de dez do corrente que em resposta ao officio de vinte e seis do mes passado, dirigido pelo segundo supplente desta subdelegacia, Jevo as máos de Vossa Senhoria úma copia authentica do termo que mandei lavrat, no qual estāo relscionados todos os bers do espolio do firado subdito Hespanhol Caetano Joaquim Muschuack, que foráo encontrades em poder do dito segundo supplente conforme Vossa senhoria determinou em seu citado officio, a que respondo. -Deos Guarde à Vossa Senhoria - Freguesia de Santa Anna da Bc̉a Vista vinte e quatro de Maio de mil oito centos e secenta e sete=llistrissimo Senhor Juiz Municipal do termo da Villa de Caçapava, Francisco Manoel Gomes;= Liberato Rodrigues de Freitas. subdelegado de Policia.

Está conforme o original

0 Eser $^{\mathrm{m}}$ Miguel Josed de Campos 
[Anexo n. ${ }^{\circ}$ S ao documi de 31 Julho 1867]

Copia n. ${ }^{\circ} 3$

Mlustrissimo Senhor. $=$ Accuso â recepçấo do officio de Vossa Senhoria datido em tres do passado e recebido em vinte $\mathrm{e}$ nove do mesmo acompanhando a reliação dos bens que se achão em deposito pertencentes ao subdito Hespanhol Caetano Joaquim Manchuack, que foi assasinado barbaramente no Destricto de Santa Anna da Bỏa Vista. Nesta occasião authorisei ao Senhor Julio Alves dos Santos Pessōa para tomar conta de tudo quanto pertencia ao infeliz Manchuack: este vice consulado espera que a justiça the preste todo o auxilio como the cumpre. Deos Guarde if Vossa Senhoria. Vice consulado de Hespanha em Porto Alegre quatro de Julho de mil oito contos e secenta e sete = Illustrissimo Senhor Juiz Municipal e d'Orfãos de Caçapava - Jos Francisco dos Santos. $=$ Vice Consul $=$

Está conforme o original

0 Escr ${ }^{\mathrm{II}}$ Miguel Jose de Campos

[A nexo $n^{\circ} 6$ ao documento de 03 desulho de 1867 ]

$$
\mathrm{II}^{\mathrm{mo}} \text { Señr. }
$$

Em resposta ao officio de V $S^{\text {a }}$ datado de hontem, Renetto-lhe por copia o ofticio, que me dirigio o $2 .^{\circ}$ supplente do subdelegado de Policia de Santa Anna Marcelino Dornelles doliveira, como V.S. exige.

\section{Deos Guarde if V.S ${ }^{\text {" }}$}

Carapava 23 de julho de 1867

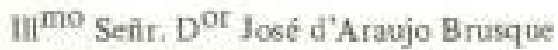

D. Juiz de Direito desta Comarca. 
[Anexo $n^{0} 7$ ao documento de 03 de Julho de 1867]

copia

lllustrissimo Senhor $=$ Participo d. Vossa Senhoria, que havendo-me em consequencia do assassinato perpetrado na pessoa do negociante hespanhol Caetano Joequim Marchuack no dia quatorse do corrente a noite, no Setimo quarteirão deste Districto, procedido o liwentario aos artigos de seu negocio, e depois de fexadas as portas e lacradas, deixando a casa sob a guarda de dous homens, e escripto aos negociantes Manoel Claudio Maciel e Luis Raffo, por constar-me de sciencia certa serem credores do finado, para que no dia vinte se acharem no domicilio do mesmo finado, e a vista de seus documentos tomarem conta do seu espolio; e como chegou no dia designado vinte do corrente o negociante Luis Raffo, quem illudindo-me com documentos, creio que antigos demonstrou o finado dever-the hu conto de reis, e andando junto desta quantia os generos achados na Casa de negocio, e afirmar-me que o outro negociante nada ali tinha, e exigindo-me as chaves da caza de negocio, eu na bou fe entreguei-lhe, e de tudo tomou conta; e na occasifo de ceu tres carretas em barcou quanto havia de negocio em questáo. no dia vinte e quatro appareceo-me o outro negociante Manoel Claudio Maciel quem por ausente de sua Residencia náo pode chegar no dia vinte como se the havia prevenido, e informando-me que naquelle negocto tinha generos consignados 20 mesmo finado, Requereo-me embargo dos generos em consequéncia do que os mesmos ficão depositados em minha Residencia no mesmo quarteirão visto que depois de comparecer o dito Maciel, mandei chamar o outro negociante que hia em retirada para seo domicilio, que he no Municipio de Piratini, $e$ achando-se ainda dentro deste Districto, nâo quis vir entender-se com o outro negociante. Respondendo-me que a muitos dias se achava fora de sua casa de negocio, a qual tinha ficado entregue somente em poder de uma escrava: per tudo isto mandei proceder so embargo requendo para acautellat os generos por ter ciente ao requerente, e como prevejo que nāo cheģarão a um acordo antigivel, fica depositado em meu poder o citado espolio até ulterior disposiçāo de Vossa Senhoria, çe me ordenani o que devo faser em tal emergencia $=$ Deos Guarde a Vossa Senhoril $=$ Freguesin de Santu Anna da Bôa Vista, vinte $\mathrm{e}$ seis de Abril de mil oito centos e secenta e sete = lllustrissimo Senhor Juis Municipal de Termo da Villa de Caçapava = Marcelino Dornelles d'Olivei$\mathrm{ra}=$ Sudelegado em exercicio

Estí coaforme o original

O Escr:- Miguel Jose de Campos 
[Anexo ${ }^{\circ}{ }^{\circ} 8$ ao docum. de 3 de Jutho - 1867 ]

\section{$\mathrm{Illm}^{\circ} \mathrm{Snt}$}

Accuso, hontem a noite, haver recebido o officio de V.S. de 15 do corrente, ordemando-me informe com urgencia $e$ circonstanciadamente, sobre a arrecadaçäo dos bens deixados pelo subdito Hespanhol Caetano Josquim Marchuack; por constar a V S, que eu tomei conta dos ditos bens por pazamentos de dividas: sobre o que cumpre-me informar a V.S., que por ordem do Sr. Juiz Municipal do Termo, me dirigi no dia 22 de Maio do corrente anno, to lusgar ondés se achárăo ditos bens, e ahi relacionei-os minuciosamente, entregando-os $\mathrm{em}$ deposito $\mathrm{em}$ poder do Cidadão Severino Dornelles de Oliveira, que assignou termo de fiel depositario, e dirigi huma copia autentica do dito termo, ao dito Snr. Juiz Municipal. Quando prestei juramento do cargo, jí se achavío os citados bens em casa do dito depositario, arrecadados a ordem de sagundo supplente désta subdelegacia; assim pois ninguesn tomou conta de taes bens por pagamento de dividas, e se achĩo depositados a disposiçio das authoridades competentes, posto que sejāo crëdores ao espólio Luiz Raffo residente no Muricipio de Piratiny e Alf ${ }^{5}$ Manuel Claudio Maciel, no da Encruzilhada: isto é quanto tem occorrido a respeito.

1867.

Dees Guarde a V.S.Freguesia de Sant'Anna da Bòa Vista, 17 de Julho de

$111 \mathrm{~m}^{\circ}$ Snr. $\mathrm{D}^{\text {Or }}$ Juiz de Direito, José de Araujo Brusque

Liberato Rodrigues de Freitas

Subdelegado de Policia

[Anexo $n^{\circ} 9$ ao documento de 03 deJutho de 1867 ]

$$
111 \mathrm{~m}{ }^{\circ} \mathrm{Snr} .
$$

Em resposta ao officio de V.S. datado de 19 do corrente, cumpre-rne informar, que depois que occorreu o assassinato do subdito Hespanhól Caetano Joaquim Manchuack no dia 14 de Abril, no dia seguinte se dirigio a casa do assassinado, e fez auto de corpo de delicto no cadaver, o segundo Suppleate désta Subdelegacia Marcellino Domelles de Otiveira, emtão em exercicio, depois do que relacionou os bens que encontrou pertencentes ao finado, e lacrou as portas, e póz sob a guarda de dous homens e escreveu tos negociantes Luiz Raffo e Mancel Claudio Maciel; para que no dia 20 do dito mez se achassem na dita casa em que residin o finado, para fomarem conta do 
espolio, por que the constaru serem credores ao mesmo, e que no dia designado ali chégiro o negociante Luiz Rafto, a quem fẻz entrèga das chaves da casa, por ignorar que houvesse tratados de reciprocidade com a naçăo Hespanhola, e nāo esperou mais tempo pela vinda do outro credor, pot o dito Raffo the affirmar que elle só éra o erèdor, e que co bens não chepaväo para seu pagamento, e a tado se prestou de bôa fé, e avista đe đocumentos que the mostrou, assignados pelo finado: em consequencia o sobredito Raffo fezz carregar em tres carretas quanto existia, neste interim chegou o outro crèdor Maciel, e näo encontrando mais a Raffo, requereu embargo dos ditos bens, pedindo os depositasse em easa de Severino Domelles de Oliveira, o que fèz. Depois da informaçiro que dei a V.S. em 17 do corrente, me informei minuciosamente do que acima relato; assim como consta-me mais que o supra-citado Raffo disposéra de alguns generos no valor de duzentos e tantos mil reis, isto sei por me affirmar o mesmo Raffo que se achảva presente na occasião que recebi o officio de V.S. que ora respondo, e quem me đisse, que não tinha intenção de occultar quanto fèz, e que em tempo havia de apresentar todas as contas correntes.

Deos Guarde a V.S.

Freguezia de Sant'Arina đa Bóa-vista, 23 de Julho de 1867

Illm ${ }^{\circ}$ Snr. D
Jut Josiz de Direito da Comarca de Caçapsva.
Liberato Rodrigues de Freitas
Subdelegado de Policia

$111 \mathrm{~m}^{\circ} \mathrm{e} \mathrm{Exm}^{\circ} \mathrm{Snr}$

O abaixo assignado tem a honra de acuzar a recepsalo do Officio, que V.E. the firigio em dacta de 8 do corrente relactivo a um opusculo publicado n'Europa por Charles Expilly no anno pp e que se refere so tractamento, que o Govemo do Brasil dá acs presioneiros Paraguaios que se tenderảo na Unguaỹzanna, dizendo, que săo vendidos!!!

O abaixo assignado Vice Consul de Hespanha nesta Cidade, onde permaneceráo os Paraguaios presioneiros por muitos meses, tem a hona de dizer a V.E., que é falço c falcissimo tudo quanto se publicou neste sentido no opusculo de Charles Expilly, assim como são outras muitas publicaçoens que se tem feito n'Europa relactivas n'America.

O Sabio Governo de S.M. o Imperador do Brasil, sempre tractou e tracts os presioneiros. Paraguaios como homens livres e quando elies aqui chegratos, eu hindo dezempenhar as funçōens do meu cargo $\mathrm{O}$, sabendo se existia algum Hespanhol entre elles para o reclamar, soube que o Governo do Brasil thes dava, roupa, caza, comida, fumo, erva matte, dusentos teis diarios, e as authoridades locaes thes pemitiåo trabalhar nas obras particulares para si; eu mesmo Exm ${ }^{0}$ Snr, por muitas vezes os occupei no meu serviço particular em arrumar madeira que costumo receber dos meus Engenhos de Cerrar.

0 abaixo assignado lamenta que Charles Expilly se attevesse afaltar tanto d verdade escrevendo para o pubilco. Outro sim, querendo o abaixo assignado engajar atguns 
presioneiros que soubessem fabricar a erya-matte para os empregar em uma Fasenda que tem, se đirigio ao então Presidente, osr Visconde da Boa Vista, e nao pôde conseguir estè engajamento por me dizer S. Ex ${ }^{\text {cia }}$, que o Govemo queria te-tos juntos para serem restituidos quando $s e$ fizesse a paz. Isto $e$ o que se passou nesta cidade com respeito a presioneiros Paraguaios a que posso attestar sob a fè das minhas funçoens publicas.

Aproveito a oportunidade para renorar a V.E. os meus protestos de estima e destincta concideração á pessoa de V.E. Vice Consulado de Hespanha em Porto Alegre 11 de Julho de 1867 .

$1 \mathrm{Im} \mathrm{m}^{\circ}$ e Exm ${ }^{\circ}$ Sru $\mathrm{D}^{\text {Ot }}$ Francisco Ignacio Marcondes Homem de Mello,

Presidente desta Provincia.

Joak F $\tan ^{\mathrm{co}}$ dos Santos

Vice Consul

$$
\text { Him }{ }^{\circ} \text { Exm }{ }^{\circ} \text { Snr. }
$$

0 abaixo assignado Vice Consul de S. M. Catholica, tem a honra de levar ao conhecimento de V.E., que o subdito hespanhol José Puegols, que se achava prezo na cadeia desta Capital foi também comprehendido na leva de prezos que ultimamente embarcou para o Rio de Janeiro; este subdito de S.M. Catholica não podia ser comprehendido resta medida, por quanto o julgamento dele a inda pende da decizâo da rellaçăo do districto para onde appelou da sentença que injustamente the foi impósta peio juiz Municipal de Itaqui, e o abaixo assignado espera que V.E. expeça suas ordens para que seja novamente remetido a esta Capital onde deve esperar o resultado do seu julgamento: outro sim pede o abaixo assignado a V.E. que se digne ordenar ís authoridades locaes o cumprimento do artigo 10 da Convençăo Consular, pot quanto sendo barbaramente assacinado á mezes o subdito de V.M. Catholica, Caetano Joaquim Murctuack no districto de Santa Anna da Boa Vista, a inda noo houve uma authoridade Policial que communicasse esta mórte a este Vice Consuladol

0 abaixo assignado tem a subida honra de significar a V, E. os seus protestos de consideração e respeito

Vice Consulado de Hespanha em Porto Alegre

7 de Novembro de 1867

Illm ${ }^{\circ}$ e Exm ${ }^{\circ}$ Snr D ${ }^{\text {Ot }}$ Francisco Ignacio Marcondes Homem de Mello Presidente da Provincia. 
Vice Cosisulado de Esparia

en

Rio Grande del Sur

$\operatorname{Illm}^{0}$ Ex. ${ }^{\mathrm{mo}}$ Senr

Tenho a honra de accusar recepçáo da Circular de V.Ex ${ }^{2}$ se dignou comunicar-me haver n'esse mesmo dia tomado posse do cargo de Presidente d'esta Provincia, para o qual sua Magestade o. Imperador houve p. bem nomear a V.Ex ${ }^{\text {a }}$.

Agradecendo a V. $\mathrm{Ex}^{\mathrm{a}}$ tăo honrosa communicação prevaleço-me da opportunidade para appresentar a V. $\mathrm{Ex}^{\mathrm{a}}$ os protestos de minha particular estima e consideraçăo.

Deos Guarde a V. Ex ${ }^{\text {a }}$ Vice Consulado de Hespanha na

Cidade do Rio Grande 5 de Fevereiro de 1867.

IIlm ${ }^{\circ}$ Exm $^{\circ}$ Senr.

Fran ${ }^{\mathrm{CO}}$. Ignacio đe Marcondes Homern de Mello

M.D. Presidente d'esta Provineia

Vice Consul de Hespenha

Zeferino A. d'Azambuja

Vice Consulado de Hespanha em

Uruguayana 24 de Fevereiro de 1867

\section{Exmo. Señ̂ ;}

Tenho a alta honra acusar o Oficio de V Exa. datado de 22 de Janeiro ultimo en que se digha comonicar que S M o Imperador houve por bem nomear a V Exa- por carta Imperial de 27 de Dezembro, Presidente desta Provincia tomando posse no dia 22 de Janeiro.

Cumpreme por tal plausivel nomeaçäo, Exmo. Señ̃, felecitar em Nome de S M Catholica, a V Exa. por ter assumido o importantissimo o honroso cargo, primeira Authoridade desta Provincia.

Este Vice-Consulado sproveita apresente oportunidade para segnificar a V Exa. o alto e merecido respeito que the he devido, a quem Deos Guardo a muitos annos.

\section{Antanio Morjaratin}


Vice Consulado de Hespanha em Uruguayana 24 de Março de 1867

$$
11 m^{\circ} \cdot \text { Exm }{ }^{\circ} \cdot \text { Senr. }
$$

Tenho a honra em accusar o recibimento do officio de V.Exm ${ }^{\mathrm{a}}$, datado de 8 do passado, recebido no dia 7 do corrente, no qual V.Exm ${ }^{\mathrm{a}}$ - se digna communicar-me que, n'squella data expedia ordem a Thesouraria da Fasenda desta Provincia, para determinar a Alfandega desta Villa, fazer-me entrega do producto dos espolios dos subditos Hespanhoes Joẫo José Visanco e Joâo José Berrotaran.

Tendo me derigido em data de 20 do Corrente ao Sens. Inspector da Alfandega, para saber se tinha chegado algumas ordens da Thesouraria sobre as ditas entregas; me fol respondido, que até aquella data, ordem nemhuma tinha sido expedida pela Thesouratia da Fazenda a tal respeito o que me cumpre communicar a V.Exm ${ }^{\mathrm{a}}$. para seu conhecimento.

Sirva-se V.Exm ${ }^{2}$. aceitar os respeitosos comprimentos o felicitaçōes que the tributa este Vice Consulado.

Decos Guarde à V. Exma .

Antonio Monjardim

IIIm ${ }^{\circ}$. e Exm ${ }^{\circ}$. Senr. Presidente da Provineta do Rio Grande de S. Pedro do Sul.

[Anexa as documento de 24 de Marzo de 1867]

IIImo. Exmo. Sent.

Levo ao conhecimento de V Exa, , por copia as duas notas que dirigio a este Juiso o Vice Consul de Sua Magestade Catholica, requisitando que se posesse a sua disposiçijo o producto das arrecadaçbes de espolios de subditos hespanhóes feitas por este Juiso, solicitando uma relaçāo dos bens arrecadacos por este Juiso de subditos d'essa naçio.

Pela resposta que del do mesmo, constante da copia junta e relação que remetti, conheceri V Exa. se haver unicamente arrecadado por este Juiso os espollos dos subditos hespanhóes fallecidos absintestados e sem deixarem hezdeiros no lugar, Joâo Jost Berrotaran e Jolio Jose Vivanco nos annos de 1859 e 1860 , tendo o producto desses espolios constantes da referida nota junta por copia sido eatregues n'Alfandega desta Vilia, com producto de herança de ausentes : 
E tendo occorrido estas arrecadaçōes antes de existir o tratado approvado pelo Decreto $\mathrm{n}^{\circ} 3136$ de $10^{\circ}$ de Julho de 1863 , entrel em duvida se pode este Juiso mandar entregar ao referido Vice Consul essas quantias ; e mesmo no caso de dever ser entregue se $\hat{\varepsilon}$ este Juiso Competente para deprecat essa entrega i Alfandega desta Villa .

Rogo por tanto a V Exa, se sirva resolver esta questão.

\section{Deos Guarde V Exa.}

Villa de Unuguayanna, 11 de Janeiro de 1867.

Illmo Exmo Sent. Presidente da Provincia

\section{O Juiz de Orfăos e Auzentes Substituto \\ Francisco Jose Coetho}

[Anotaculo ao docamento de 24 de Marpo de 1867]

O ponto sobre que versa u nota do Consul Hespanhol é o do art. 10 \$3 da convençăo, aprovada pelo decreto $\mathrm{n}^{\circ} 31=36$.

Sobre a materia da duvida do Juiz de Orphisos de Uruguaiana já expedirăo-se as ordens eonstantes das duas minutas juntas.

Dewo ainda dizer, que parece-me incontestavel a competencia do Juiz de Orphāo pat fazer a deprecada, de q̄. falla no final de seo officio.

Juigo $q$. se the responderi bem, dandorethe conhecim. ${ }^{\text {to }}$ dos officios dirigidos a Thesouraria e ao Consul em 8 de Fevereiro corrente

Em conformidade

[Anexo ao documento de 24 de Margo de 1867 ]

Mustrissimo Senhor. Pelo Decreto mumero trez mil cento $e$ trinta e seis de primeiro de Julho de mil oito centos e sessenta e trez teferente a Convençāo Consular, celebrada entre este Imperio e o Reino de Hespanha, concede o direito aos Consules e Vice-Consules da mesma administrar e liquidar as herarças de seus subditos estabelecidoc em ambos os paises ainda mesmo quando os herdeiros sejso de menor idade. Em conformidade pois com o referido Decreto me ordena o Exellentissimo Senhor Ministro de Sua Magestade Catholica, residente no Rio de Janeiro em officio de desentove de 
Setembio do corrente anno, que no caso de existirem nos oofres quantias pertencentes a ab-intestatu de subditos hespanhoes falecidos n'este Municipio, reclamar ellas a Authoridade competente para que me sejäo entregues. A vista pois da referida Convenção Consular, e do reclamo que se me ordena, me dirijo a Voesa Senhoria para que se sirva obrar o que julgar de justiça sobre a entrega das quantias existentes no cofre, pertencentes a subditos hespanhoes fallecidos neste Municipio, afim de que passīo a seus legítimos herdeiros como o determina o Artigo des da dita Convençăo Consular. Aproveito esta oportunidade para oferecer a Vossa Senhoria os protestos de minha cordial consideraçắo. Deus Guarde a Vossa Senhosia Vice Consulado de Hespanha em Uruguayanna trinta de Outubro de mil oito centos e sessenta e seis. Antonio Monjardim Vice Consul de Sua Magestade Catholica. Illustrissimo Senhor Juis Municipal Orphãos e Ausentes deste Municipio.

Está conforme ao próprio original.

Utuguayanna 9 de Janeiro de 1863

Escrivకo: João Nobre d'Almeida.

[Anexo ao documento de 24 de Marpo de 1867]

Vice Consulado de Hespanha de Uruguayana desesete de Dezembro de mill sito centos e sessenta e seis. Illustrissimo Senhor. Em trinta de Outubro do Corrente anno officiei a Vossa Senhoria afim de que se servisse ordenar a enttrega das quantias existentes no cofre pertencentes a subditos hespanhóes fallecidos ab intestato como o determina o Decreto numero tres mil cento e trinta e seis mencionado no dito meu officio a o qual não tenho tido até hoje soluçāo de Vossa Senhoria, e sendo-me necessario cumptir as ordens que tenho a tal respeito, rogo a Vossa Senhoria se sirva responder o que tiver por conveniente. Para orientar a o Excelentissimo Sunhor Ministro de Hespanha do numero de hespanhóes fallecidos $a b$ intestatu e com testamento afim de conhecerse quaes os que estäo no caso do dito mencionado Decreto, rogo a Vossa Senhoria se sirva ordenar que o respectivo Escrivão de Ausentes extraia uma relaçăo circunstanciada dos inventários de subditos hespanhbes fallecidos em conformidade com os artigos segundo, terceiro e quarto do regulamento a que se refere o Decreto numero oitocentos e cincoenta e cinco de oito de Novembro de mil oito centos e cincoenta e urn. Deus Guarde a Vossa Senhoria muitos annos Illustrissimo Senhor Juis Municipal Orphăos e Ausentes. Antonio Monjardim Vice Consal de Hespanha.

Esta conforme ao proprio original. Uruguayana 9 de Janeiro de 1867

o Escrivå Jođo Nobre d'Almeida. 
[Anexo ao documento de 24 de Março de 1867]

\section{Copia}

Juiso de Orphãos e Ausentes da Villa Uruguayanna e seu termo trinta e um de Desembro de mil oito centos e sessenta e seis. Illustrissimo Senhor. Tenho presente as notas que Vossa Senhoria dirigiu a este juiso na qualidade de Vice Consal da Nação Hespanhola neste termo, em dactas de trinta de Outubro e desesete do corrente, reclamando, que em cumprimento do disposto no Decreto numero tres mil cento e trinta e seis de primeiro de Julho de mil oito centos e sessenta e tres referente a Convenção Consular celebrada entre este Imperio o o Reino de Hespanha, e ordem que teve do Excellentissimo Ministro de Sua Magestade Catholica funto ao Governo Imperial, este Juiso punha a disposiçžso de Vossa Senhoria as quantias arrecadadas pertencentes a subditos hespanhoes fallecidos ab intestados n'este termo que existirem depositados nos cofres deste Juiso ; e bern assim pede mais uma relaçẩo extrahida pelo escrivăo d'este Juiso dos subditos hespanhoes fallecidos ab intestados $\mathrm{c}$ com testamento que constarem no mesmo. Logo que recebi o primeiro officio de Vossa Senhoria determinei ao Escrivăo deste Juiso a verificaçăo das quantias pelo mesmo arrecadadas de subditos hesparhices, mas retirandose n'aquelles dias o Escrivão que então servia o officio de Orphãos e ausentes por ter feito troca do cartório com o segundo Tabelliāo da Crus Alta ficarăo todos os cartorios desta Villa a cargo do Escaiva Siqueira, e a grande afluencia de trabalhos principalmente era feitos crimes, que pesarıo sobre este Escrivăo o impedirão de cumprit esta determinaçăo com mais brevidade. Obtendo agora essa relaçao junto a envio a Vossa Senhoria e por ella verá que apenas se tem arrecadado os espolios de dous subditos hespanhóes fallecidos intes. tados e sem terem deixado herdeiros no lugar ; sendo o primeiro João José Berrotaran cuja arrecadaçă foi começada no anno mil oito centos cincoenta e nove e lerminada no seguinte, tendo sido recolhido o seu producto constante da referida nota đo Escrivio ao cofre d'Alfandega d'esta Villa onde ficou tảo bem depositado um bahú com os papeis do referido finado, que se póde requisitar a entrega quando Vossa Senhoria o quiser receber. Como verá da referida nota tambem arrecadou-se por este Juiso o espolio do subdito hespanhol fallecido intestado João Jose Viranco, no anno mil oito centos e sessenta e o seu liquido producto foi pela mesma forma recollido ao cofre da Alfandega désta Villa tendo essas quantias eatrado nos cofres publicos na forma dos Regulamentos anteriores, nāo existindo em cofres que estejwo sob as immediatas đisposiç̄ēes deste Juiso para poder mandar pór á disposiçĩo de Vossa Senhoria, nesta datı peço para esse fim esclarecimentos ao Excellentissimo Senhor Presidente da Provincia. A proveito a opportunidade para saudar a Vossa Senhoria como Vice-Consul de Sua Magestade Catholica n'esta Villa, e significar-lhe a consideraçîo que lhe tribato. Illustrissimo Senhor Dom Antonio Monjardim Vice Consul de Sua Magestade Catholica. Neste termo. O Juis de Orphĩos e ausentes em exercicio -Francisco Jose Coelho.

Está conforme ao proprio original .

Uruguayana 9 de Janeiro de 1867

O Escrivăo Jos̄o Nobre d'Almeida 
[Anexo ao documento de 24 de Março de 1867]

\section{Copia}

Jođo Nobre d'Almeida Escrivão serventuario vitalicio de Juiso de Orphăos e ausentes, n'esta villa da Uruguayanna por Sua Magestade o Imperador Aquem Deus Guarde et cetera. Certifico que por ordem do Senhor Juiz de ausentes substituto em exercicio cidadāo Francisco Jose Coelho, e a requisiça do Vice Consul de Hespanha, dei busca $\mathrm{em}$ meu cartorio, e n'elle só deparel com dous autos de arrecadaçăo de subditos hespanhóis que fallecerão neste termo, ambos ab intestados, e são os que se seguem. Arrecadaçĭo dos bens do hespanhol João José Berrotaran começada no anno de mil oito centos cincoenta o nove e concluida no anno mil oito centos sessenta $e$ um, todos os bens desta arrecadaçato tanto moveis como de raiz e semoventes forão arrematados em hasta publica e leilso, e o seu producto recolhido acs cófres na Alfandega desta Villa, sendo o primeiro conhecimento de entrada datado de vinte einco de Janeiro do anno mil oito centos sessenta, da quantia de dois contos cinco mil e sete reis. Em desoito de Maio do mesmo anno acima, consta pelas contas apresentadas pelo curador da berança e não pelo conhecimento junto aos autos, ter entrado para o cofre a quantia de oito centos trinta e tres mil e quatro centos reis. Finalmente o ûttimo conhecimento de entrada é datado de desesete de Junho de mil oito centos sessenta e un da quantia de reis um conto quatro centos noventa e cinco mil e oitenta e oito reis; porem desta quantia deve abater-se a de trinta e dous mil ceato e sessenta reis que fol levantada do cofre para pagamento de decimas ubbanas que o mesmo finado devia, $e$ talves mais as despesas desse alevantamento que nấo consta dos autos. Existe mais na Alfandega um bahu com papeis que devem estar lacrados: Desta arrecadaçăo é o que ha. Segunda arrecadaçắo dos bens do subdito hespanhol Joáo José Vivanco, começada e concluida no anno de mil oito centos e sessenta. Todos os bens desse finado forro arrematados en hasta publica; e recolhido pela primeira vez em data de trinta de Abril de mil oito centos e sessenta, como consta do conhecimento em forma junto dos respetivos autos, foi recolhida ao cofre a quantia de tresentos e cinco mil reis em nove onças de ouro e uma moeda também de ouro de desesete mil reis. $O$ segundo conhecimento é datado de desenove de Maio do mesmo anno da quantia de quarenta e seis mil trezentos e des reis. Abate-se porem quarenta e quatro mil cento e nowents de custa da arrecadaç̧̃o que apesar de năo constar dos autos, sem duvida forăo pagas pelos cofres e das quantias acima. Nada mais tenho a certifiear alem do que acima fica transcripto que tudo parto por fé. Uruguayana vinte dous de Dezembro de mil oito centos sessenta e seis, Eu João Nobre de Almeida escrivăo de Orphāos o escrevi e assigno. João Nobre de Almeida.

Está conforme ao original.

Uruguayana 9 de Janeiro de 1867

o Escrivão Joāo Nobre d'Almejda

2.005:007

$833: 400$

1:495;088

$305: 000$

46:310

44:190

307:120

he o que

fica 
[Anexo ao documerto de 24 de Margo de 1867]

Vice Consulado de Hespanha em Uruguayanna 17 de Março de 1867

$$
\text { Ilm } m^{\circ} \cdot \mathrm{Ex}^{\mathrm{mo}} \cdot \text { Senr. }
$$

Tenho a alta honra em dirigirme $\triangle$ V.Ex ${ }^{2}$, afim de merecer de V.Ex ${ }^{2}$. uma graça.

Meu filho Jošo Rodriguez. Monjardim Cidadao Bratleiro de idade de 24 annos he o Secretario d'este Vice Consulado desde a sua instalação, e nunca se the assentou praça por ter atestado de doente; $\mathrm{f}$ eu estando como estou na avansada idade de 54 annos, me he muito pezado o seu Expediente, são estes os poderosos motivos $\mathbf{E x}^{\text {mo }}$. Señr. que me obriga implorar a graça para que se digne Ordenar que se the de uma Portaria, eximindo-o do Serviço Militar.

Este Vice Consulado aproveita apresente oportunidade para significar a V.E. a o alto emerecido respeito que the tributa. Deos Guarde a V $\mathrm{Ex}^{\mathrm{a}}$ - muitissimos annos.

\section{Antonio Monjardim}

$1 \mathrm{ll} \mathrm{m}^{\circ}$, e Ex ${ }^{\mathrm{mo}}$. Senr Prezidente ds Provincia do Rio Grande do Sul.

[Aneco ao documento de 24 de Marpo de 1867]

Vice Consulado de Hespanha em Uruguayanna 5 de Janeito de 1867

$$
\mathrm{Ex}^{\mathrm{mo}} \text { Sär }
$$

Tenho a honra em dirigirme a V.Ex ${ }^{2}$ comonicando que $\mathrm{cm} 30$ de ouctubro último me dirigi so juiz de Orfáos e suzentes desta Vilia reclamando as quantias depositadas no cofre destr Alfandega pertençentes abintestados de Subdictos hespanhoes fallecidos; e nto tendo obtido resposta desde aquella dacta íthe 31 de Dezembro, a duas noctas minhas deripidas atal firm; e sendome ordenado pello Exm ${ }^{\circ}$ Ministrode hespanha residente junto ao Goverso Imperial que no caso de năo obter um pronto e favoravel resul tado por parte deste juizo dirigime a V.Exa afim de obter a justiça devida.

No dia 3 do corrente recibi em resposta o Officio do Juiz de Orfáos e auzentes que por copia remetho a V $\mathrm{E}^{\mathrm{a}}$ afim de que inteirado delle se digne providenciar o que tiver $\mathrm{V} \mathrm{E}^{\mathrm{a}}$ por comveniente, para que por parte deste juizo não se demore a entrega do ezistente no cof re deata Alfandega us quantias pertencentes aos espolios de Jexio José Berrotaram, e Jobio José Vivanco para passar a seus ligitimos herdeiros, 
Aproveito apresente oportunidade para que V.Ex, ${ }^{a}$ se digne aceitat os protestos dis distinta concideração e respeito devido.

Deos Guarde a V.Ex. ${ }^{a}$

$\mathrm{M}^{5} \mathrm{An}^{8}$

O Vice Consul

Antonio Monjardim

$\mathrm{Ex}^{\mathrm{mo}}$. Sñr. Vice Prezidente da Provineia do Rio Grande de S. Pedro do Sul

[Anexo ao documento de 24 de Março de 1867]

Copia = Juiso de Orfíos e ausentes da Villa Urugusyanna e seu termo, 31 de Dezembro de $1866=$

Wlimo Sñr = Tenho presente as notas que V.S. dirigio a este Juiso, na qualidade de Vice Consul da Nação Hespanhola neste termo em datas de 30 de Outubro e 14 do corrente, reclamando, que em cumprimento do disposto no Decreto n. ${ }^{\circ} 3 ; 136$ de $1 .^{\circ}$ de Julho de 1863 referente a convenção consular celebrada entre este Impétio e o Reino de Hespanha e ordem que teve do Ex ${ }^{m o}$ Ministro de Sua Magestade Catholica junto ao Governo Imperial, este Juiso ponha a disposição de V.S. as quantias arrendadas pertencentes a subditos Hespanhóes fallecidos abintestados neste termo que existirem óepositados nos cofres đeste Juiso; e bem assim pede uma relaçalo extrahida pelo Escrivilo deste Juiso dos subditos. Hespanhóes fallecidos abintestados e com testamentos que constarem no mesmo. - Logo que recebi o $1 .{ }^{\circ}$ Officio de V S. determinel ao Escriváo deste Juiso a verificaçăo das quantias pelo mesmo arrecadadas de subditos Hespanhióes : mas retirando-se n'aquelles dias o Escrivăo que então servia o offício de Orfáos e ausentes por ter trocado o cartório com o do $2 .^{\circ}$ Tabeliāo da Crusalta, flesráo todos os cartórios Uesta Villa a cargo do Escrivão Siqueira, e a grande afluéncia de trabalhos, principalmente em feltos Crimes, que pesarão sobre este Escrivão o impedirăo de cumprir esta determinaçlo com mais brevidade.

Obtendo agora essa relaçăo, junto a envio a V.S. pot ella verd que apenas se tem arrecadado os expolios de dois subditos hespanhós falecidos intestados e sem terem deixado herdeiros no lugar, sendo o $1^{\circ}$ de Jotio José Berrotaram cuja arrecadaçío foi começada no anno 1859 e terminada no seguinte, tendo sido recolhido o seu producto constante da referida nota do Eserivão, ao cofre da Alfandega desta Villa onde ficou também depositado um bahu com os papeis do referido finado, que se pode requisitar a entrega quando $\mathrm{V}$. S. o quiser receber-como verá da referida nota também arrecadou-se por este Juiso o espolio do subdito hespanhol fallecido intestado Jolio José Vivanco, no ano de 1860 e o seu liquido producto foi pela mesma forma recolhido ao Cofre da Alfandega desta Villa. - 
Tendo essas quantias entrado nos Cofres públicos na forma dos Regulamentos anteriores, nđ̄o existindo em cofres que estejấo sob as immediatas disposiços deste Juiso para poder mandar pôt a đísposiçāio đe V. $\mathrm{S}^{\mathrm{a}}$, nesta data peço para este fím exclarecimentos ao Ex ${ }^{\text {Do }}$ Snf Presidente da Provincia. - Aproveito a opportunidade para saudar a V.S. com Vice Consul de S. Magestade Catholica nesta Villa e significar-the a consideração que lhe tributto $=$ Illmo. Sîr $D^{\mathrm{n}}$ Antonio Monjardim = Vice Consul de S.M. Catholica neste termo $=0$ juis de Orphấos $\mathrm{e}$ ausentes em exercicio $=$ Francisco José Coelho.:

Vice-Consulado de España en Bage

$$
\text { III. }{ }^{\mathrm{mo}} \text { y Exmo. Señor. }
$$

Mự Señor milo :

Tengo la honra de contestar al Oficio que con fecha 13 de Abril ultimo VE. se digno dirigirme, comunicandome que en aquella misma fecha V.E. tomó cuenta de la administracion de esta Provincia en calidad de primer Vice - Presidente

Al felicitar if V.E. por tan distinguido cargo, me cabe el alto honot de manifestar a V.E. mis humiides deseos, de que la Divina Providencia se digne dispensar á V.E. toda clase defelicidades en su đificil é importante administracion .

Con este motivo Exmo, Señor, ruego d V.E. sesirva aceptar tas seguridades de mi mas distinguida consideracion .

Dios guarde a V.E.

Bagé 12 de Mayo de 1868.

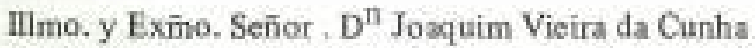

Dign. mo Primer Vice-Presidente de la Provincia de Rio-Grande del Sud.

111 $^{\text {mo }}$ y Exf̆ho. Sefior.

El Viceconsul de España

Ramon Galibern 
Vice-Consulado de Espafia

en

Bapé

III. ${ }^{\text {mo }}$ y Exmo. Señot

\title{
Muy Señor mio
}

Tengo la honra de acusar recibo de la Circular que con fecha de 14 de Julio ultimo se ha dignado V.E. dirigirme, en cual se sirve participarme, que en aquella fecha tomó posesion del cargo de Presidente de esta Provincia, para el cual fue nombrado por Carta Imperial de 13 de Junio proximo pasado.

Al felicitar á V.E, por tan distinguido cargo, cabeme la satisfacion de patentear a V.E. los sinceros deseos que me animan, para que la Divina Providencia se digne concederle toda classe de felicidades en su importante administracion.

Con este motivo Snr. Presidente, ruego a V.E. se digne aceptar las seguridades de mi mas distinguida consideracion

Dios guarde a V.E.

\section{Bagé 4 de Agosto de 1868}

III $^{\text {mo }}$ y Exmo. Snr. General D $D^{\text {n }}$ Guillermo Xavier de Souza

Dign ${ }^{\text {mo }}$ Presidente de la Provincia de Rio Grande del Sud

\author{
III. ${ }^{\text {mo }}$ y Exmo. Señor \\ El Vice-consul de España \\ Ramon Galibern
}

[Anexo ao doc. de 4 de Agosto de 1868]

$$
11 m^{0} \text { Exm }^{\circ} \text { Snr. }
$$

$\mathrm{O}$ abaixo assignado Vice Consul de Sua Magestade Catholica nesta Cidade tem a honra de accusar a recepçato do officio que the dirigio o $\mathrm{Illm}^{\circ}$ e Exm${ }^{\circ} \mathrm{Snr} \mathrm{D}^{\text {or }}$ israel Roiz Barcellos com dacta do $1^{\circ}$ do corrente em que the communica haver sido exonerado por Decreto de 20 do mes próximo passado de Presidente desta Provincia o Exmo Snr. Marechal de Campo Guilherme Xavier de Souza e haver tomado posse d'administraçāo desta Provincia na qualidade de seu primeiro Vice Presidente.

O abaixo assignado appreciando a finesa com que o Exm ${ }^{\circ}$ Snr $D^{\text {or Barcellos }}$ acaba de tractar ao Vice Consul de S.M. a Rainha de Hespanha (que Deus guarde) dirige a $\mathrm{Sua} \mathrm{Ex}^{\mathrm{cia}}$ os seus sinceros parabens pelo eminente Cargo de que se acha revestido e se 
congratula com os habitantes desta bella Provincia pela sabia Administraçăo que V.E. vai fazer com seu acrisolado patriotismo e alta inteligencia.

Prevaleç-me desta opportunidade para ter a subida honra de signifiear a V.E. o meu maior respeito e consideração.

Vice Consulado de Hespanha em Porto Alegre 3 de Agosto de 1868

$\operatorname{Illm}^{\circ}$ e Exm ${ }^{\circ} \mathrm{Snr} \mathrm{D}^{\text {or }}$ Israel Roiz Barcellos Dignissimo Vice Presidente desta Provincia

\author{
Jozé Fran ${ }^{\mathrm{CO}}$ dos Santos \\ Vice Consul
}

Vice Consulado de España

En

Pelotas

Pelotas Abril 25 de 1868

$\mathrm{Ex}^{\mathrm{mo}} \mathrm{Sar}$.

He sido honrado con el Oficio de V.E ${ }^{\text {a }}$, fha 13 del peesente, comunicandone, haver V.E. ${ }^{2}$ asumido la Presidencia de esta Provincia en la cualidad de $1^{\text {et }}$ Vice Presidente.

Agradeciendo a V.E. la connmicacion, $q{ }^{e}$ se servio dirijirme y felicito a V.E. ${ }^{3}$ per el motivo que la dietó.

Aprovecho la ocasion Ex ${ }^{\text {mo }}$ Señr, para presentár a V. E ${ }^{a}$ el homenaje de mi distinta consideracion y estima.

\title{
Benito Maurell
}

III. Ex ${ }^{m}$ Sñr Doctor Joaquim Vieira da Cunha, $1^{\text {er }}$ Vice Presidente en esercicio de esta Provincia de San Pedro del Sur. 
Vice Consulado

de España

Pelotas Mayo 151868.

Exmo. Senir Vice Presidente.

Retirandome hoy para Europa temporariamente, pongo en conocimiento de V. $E^{a}$, que con autorisacion del Señi Ministro de España en Rio de Janeiro, queda encargado durante mi aucencia, de este Vice Consulado, mi hijo Benito Maurell y Lamas, Vice Consul Oriental.

Aprovecho esta ocasión para reiterár a VE. ${ }^{\mathrm{a}}$ los protestos de mí Consideración y estima.

\section{Benito Maurell}

Illmo. Exmo. Señr Dor. Joaquin Vieira da Cunha

M. D. $1^{\text {et }}$. Vioe Presidente de esta Provincia en ejercicio.

Vice Consulado de

Españn. Pelotas Julio $24 \cdot 1868$

\section{Ex: Sîr Prezidente :}

He tenido el placér de recibit el oficio de V.E. fha 14 del presente communicundome haberse recebido de la Presidencia de esta Provincia, para la cual fue" nombrado V.E. ${ }^{\text {a }}$ por carta Imperial de 13 del mes proccimo pasado.

Agradeciendo \& VE la participacion que se digna hacerme, me felicito con los Españoles recidentes en esta Provincia por la elevación de V.E. a tan importante cargo.

Dios Guarde a V.E. muchos años.

III $^{\text {mo }}$ Ex $^{\text {mo }}$ Srr̈s Mariscal

Guillermo Xavier de Souza

M.D. Presidente de esta

Provincia \& \& \& 
Vice Consulsdo de

Pelotas Setiernbre 23. 1868

España en Pelotas

\section{Ex ${ }^{\text {mo }}$ Sefir Presideate}

He tenido el honor de recebir la communicacion de V. E. ${ }^{a}$ fha 16 del presente, anunciandome, haberse recibido V. $\mathrm{E}^{\mathrm{a}}$ en ese dia, de la presidencia de esta Provincia, para la cual fue nombrado V.E. ${ }^{a}$ per carta Imperial, del 25 de Julio pasado,

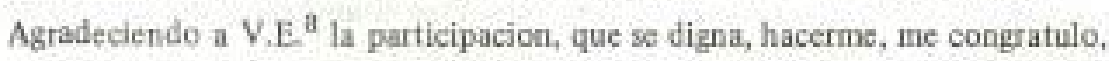
com mis compatriotas, per tal suceso.

estima.

Aprowecho ia oportuntidad para saludar a V.E. ${ }^{2}$, com toda consideracion y

$11^{\mathrm{mo}} \mathrm{e} \mathrm{Ex}^{\mathrm{mo}}$ Señr D ${ }^{\text {or }}$. Antonio da Costa Pinto e Silva

M.D. Presidente de esta Provincia de S. Pedro do Sul en Porto Alegre

Berito Maurell y Lamas

Encargado interino de este Vice Consulado

Illm? e Exm? Snr?

A abaixo assignado Vico-Consul de S.M. Catholica, tem a honra de acuzar a recepstio do officio que the dirigio o $11 m^{0}$ e Exm. Snr' D. Joaquim Vieira da Cunha com dacta de 13 do corrente, emque the participa haver tomado pósse d'Administração desta Provincia na qualidade de seu primeiro Vice Presidente.

Appreciando devidamente afinesa com que V.E. acabs de tractar ao ViceCorsul de Hespanha, este se congratuia com os habitantes d'esta Bella Provincia pela sabia Administração que V. E. vai fazer com o seu acrisolado patriotismo e a alta intelligencia, $\mathrm{e}$ como seu antigo amigo the dirige seus sinceros parabens pelo iminente cargo de que V. E. se acha revestido.

Prevaleço-me desta occaziăo para dirigir a V. E. o meu maior respeito e alta consideraçđó. Vice-Consulado de Hespanha em Porto Ale 15 de Abril de 1868,

Illm. ${ }^{0}$ e Exm? SE. Dor Joaquim Vieira da Cunha, Muito Digno Vice Presidente ún Provincia 


\section{$1 \mathrm{IIm} \mathrm{m}^{\circ} \mathrm{Exm}^{0} \mathrm{Snt}$}

0 abaixo assinado Vice-Consul de S.M. Catholica nesta cidade tem a honta de acuzar a recepsao do officio que em 16 do cotrente the dirigio o Exm ${ }^{\circ} \mathrm{Snr} \mathrm{D}^{\mathrm{ot}}$ Antonio da Costa Pinto Silva participando-lhe que por Carta Imperial de 25 de julho findo se Dignou S.M. o Imperador nomeá lo Presidente desta Provincia e que havia tomado posse n'aquela dacta.

Apreciando devidamente a finesa que V.E. acaba de tractar ao Vice Consul de Hespanha elle com os subditos de S.M. Catholica se associaío no justo contentamento á população desta berla Provincia pela acertada escolha que de V.E. fez S.M. o Imperador đo Brazil, augurando ao Governo de V.E. todas as prosperidades que promettem a alta intelligencia acrisolado patriotismo do seu primeiro Magistrado.

Prevaleço-me desta opportunidade para ter a sabida honra de dirigir a V.E. os meus cumprimentos a quem Deos Guarde. Vice Consulado de Hespanha em Porto Alegre 18 de Setembro de 1868.

Illm ${ }^{\circ}$ Exm $^{\circ}$ Snr $D^{\text {or }}$ Antonio da Costa Pinto Silva Presidente desta Provincia.

$$
\begin{aligned}
& \text { Joze Fran }{ }^{c 0} \text { dos Santos } \\
& \text { Vice Consul }
\end{aligned}
$$

Vice Consulado de España en la Villa de Uruguay 18 de Mayo de 1868

\section{Exmo Señor}

He tenido el honot en recibit el oficio de V.E. fecha 13 de Abril, en el que se digna comunicarme que en esta ultima fecha V.E. ha tomado cuenta de la administracion de esta Provincia en qualidad de $1{ }^{\circ}$ Vice Presidente.

Cumpleme por tal plausible nombramiento Exmo Señor felicitar en nombre de S.M. Catolica a V.E. por haver asumido el importantisimo y honroso Cargo de $1 .{ }^{\circ}$ Magistrado de esta Provincia.

Este Vice Consulado aprovecha la presente oportunidad para sipnificar a V.E. el alto y merecido tespecto que le tributa.

Dios guarde a V.E. $m$. años.

II ${ }^{\text {mo }}$ y Exmo Snr D. Joze Vieira da Cunha , D. Vice Presidente de esta Provincia 
Vice Consulado de Hespanha en Uruguayana 3 de Seternbro de 1868

\section{Exm. Senf}

Tenho a honra de levar ao conhecimento de V. Ex. que no mez de Maio do corrente anno, foi assasignado barbaramente e roubado seus interesses no Municipio de Sāo Borja, o subdito hespanhol José Villaplana domiciliado nesta Villa.

Em 29 do dito mez derigi uma supplica ao Delegado de Policia daquella Villa, pedindo-lhe uma informaçno do assasignato commetido, e a captura do assasigno, a quem se the atribuia o roubo, como peño que era do falecido: ao que não se dignou responder-me e deregindo-the segunda súpplica em Junho nāo mo mandou atể a data de hoje as informaçôes pedidas; as quaes sendo-me ellas exegidas pelo meu Ministro residente no Rio de Janeiro. Rogo a V. Ext se digne ordenar que aquelle Delegado dê uma informação do assasignato commettido na pessoa do dito subdito hespanhol José Villaplana e se alhi se proceder a recadaçăo de seus interesses e puniçăo do crime, pois que segundo informaçōes particulares, o assasigno se acha preso na Cadéa de São Borja.

Approveito a presente opportunidade para deregir a V. $\mathrm{Ex}^{\mathrm{a}}$ os meus respeitos.

IIImo e Exm? Senr "Dr" Isracl Roiz Barcellos

$10^{\circ}$ Vice Presidente desta Provincia

Antonio Monjardin

V/Consul de S.M.C.

Vice Consulado de Hespanha en Uruguayana.

4 de Setembro de 1868 .

\section{Exm $^{0}$ Señr.}

Tenho a honra de sceusar o recebimento do officio de V Ex, ${ }^{a}$ de $1^{\circ}$ de Agosto do corrente anno; no qual se digna communicat-me que tendo sido exonerado por decreto de 20 de Julho findo, o Exm. ${ }^{\circ}$ Señt. Marechal de Carmpo Guilherme Xavier de Souza, do cargo de Presidente desta Provincia, V. Ex. ${ }^{a}$ prestou juramento e tomou posse da administraçẫo da mesma Provincia, na qualidade de 1. ${ }^{\circ}$ Vice Presidente.

Cumpreme por tão plausivel nomeaçăo Exm. ${ }^{\circ}$ Señ̂ felicitar em nome de S.M. Catholica a V.Ex. ${ }^{2}$ por ter assumido o importantissimo cargo de 1: ${ }^{\circ}$ Magistrado desta Provincia . 
Este Vice Consulado approveita a presente opportunidade, para sipnificar a $\checkmark$ Ex. ${ }^{a} \circ$ alto e merecido respeito que lhe tributa.

\section{Deos guarde V Ex. ${ }^{\text {a }}$}

III. mo e Exm, ${ }^{\circ}$ Señr. D. I Israel Rōiz

Barcellos $1{ }^{\circ}$ Vice Presidente desta Provincia

Antonio Monjardin

V Consul S M C

Vice Consulado de Hespanha em Uruguayana

26 de Outubro de 1868.

\section{Exm. ${ }^{\circ}$ Sent.}

Tenho a honra acusar o recebimento do Officio de VEx. ${ }^{a}$ datado de 16 de setembro ultimo, no qual se digra communicar-me, que por Carta Imperial de 25 de Julho findo, VEx. ${ }^{a}$ foi nomeado a tomar posse do Cargo de Presidente desta Provineia, no dia 16 de Setembro findo.

Cumpre-me Exm. ${ }^{\circ}$ Señr, felicitar em nome de S.M. Catholica a VEx. ${ }^{2}$, por ter assumido o importantissimo o honroso Cargo, como primeiro Magistrado d'esta Prosincia.

Este Vice Consulado, approveita apresente opportunidade, para significar a VE. ${ }^{\text {a }}$ o alto e merecido respeito, que lhe tributa.

$$
\text { Deos guarde a } \mathrm{VEx}^{\mathrm{a}}
$$

III mo e Exm Señt Presidente do Rto Grande do Sul. 
Vice Consulado da Espanha

Pelotas Octubre 26.1871

Ex ${ }^{\text {mo }}$ Sen̂r Presidente

He sido honrado con la comunicacion de V. E. ${ }^{\mathrm{a}}$ fecha 20 Cor ${ }^{\text {te }}$, dignandose comunicarme haver tomado pocecion del Cargo de Presidente de esta Provincia, para el cual fué V.E. nombrado per carta Imperial de 27 de Setiembre ultimo mer cujo nombraimento me congratulo com V.E.

Aprovecho la ocaçón Ex ${ }^{\text {mo }}$ Seãr, para minifestír a S.E. a a fim de ser transmitido al Govierno Imperial, la satisfacción que nos ha causado à mi y a mis conciudadanos residentes en este Municipio, la adopcion de la Ley sobre el Elemento servil, que indudablemente traera una era de prosperidade y grandesa, para este hermoso pais.

Soy de V.E. ${ }^{\text {a }}$

Que Dios Guarde muchos años

\section{Benito Maurell}

A Su Ex. el Snt Senador Jeronimo Martinianno Figueira de Mello

M.D. Presidente dela Provincia del Rio Grande do Sul. Porto Alegre.

Vice Consulado de España en la Ciudad de Pelotas

\section{Exm ${ }^{\circ}$ Sồ}

He sido hontado con el oficio de VEx ${ }^{\mathrm{a}}$ de fha 5 del corr ${ }^{\text {te }}$ mez comunicando me que debieado seguir para la Corte el Exm ${ }^{\circ}$ Sôr Consejero Tristî̄o de Alencas Araripe, Presidente de esta Provincia asumió V Ex ${ }^{\mathrm{a}}$ la respectiva administracion en la calidad de $2^{\circ}$ Vice Presidente

Al acusar recebida tán grata comunicacion me es agradable felicitar a V Exa por tain distinguida honra, Seguro que la administracion de V.Ex ${ }^{\mathrm{a}}$ sers de inmensos. beneficios para esta importante Provincia. 
Aprovecho la oportunidad para significat a VEx ${ }^{2}$ las seguridades de mi mas distinguida consideracion y estima

Deus Guarde a VE ${ }^{\mathrm{a}}$ muchos affos

Pelotas 15 de Febrero de 1877

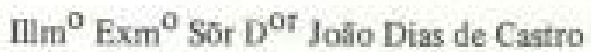

D. ${ }^{\circ}$ Vice Presidente de esta Provincia

Benito Maturell

Vice Consul

Vice Consulado de

España en la

Ciudad de Pelotss

$$
\text { Exm }^{\circ} \text { Sor }
$$

Tengo la honra de acusar recibido el oficio de V.Ex ${ }^{a}$ de fha 21 de Mayo pp. comunicandome haber tomado posecion del cargo de Presidente de esta Provincia para el cual fué V.Ex ${ }^{a}$ nombrado por Carta Imperial de 28 de Marzo ultimo.

Agradeciendo tán atenciosa comunieacion felicito a V.Ex ${ }^{\mathrm{a}}$ por la merecida honra que acaba de recibir del Gobiemo Imperial y a esta Proyincia por los inmensos benefictos que debe esperar de la esclarecida administraciôn de V.Ex².

Aprovecho la oportunidad para significar a V.Ex ${ }^{2}$ las seguridades de mi perfecta consideracion y estima.

Dios Guarde a V.Exa muchos años

Pelotas 9 de Junio de 1877

Ilim? Exmo Snr D $D^{T}$ Francisco de Faria Lemos

D. Presidente de esta Provincia 
Vice Consulado de España

En la Cludad de Pelotas

$$
\text { Exm? Sớ }
$$

Tengo la honra de acusar recibido el oficio de V.Ex ${ }^{a}$ fha 10 det corr. ${ }^{\text {te }}$ mez comunicandome haber prestado juramento y asumido ta administracion dela Provincis el dia 9 corr. ${ }^{\text {te }}$ en la calidad de $2{ }^{\circ}$ Vice Presidente.

Agradeciendo tín atenciosa comunicacion felicito a V.Ex. ${ }^{a}$ per la merecida honra que acaba de recibir del Gobierno de S.M. El Emperador (Q.D.G.) y se esta Provincia por los inmensos beneficios que debe esperar de la esclarecida administracion de V.Ex. ${ }^{a}$

Aprovecho la oportunidad para significar, a V.Ex. ${ }^{2}$ las Seguridades de mi perfecta consideracion y estima.

Dios Guarde a V.Ex. ${ }^{\mathrm{a}}$ muchos años

Pelotas 28 de Febrero de 1878

Illm Exm? Sõ D. ${ }^{\circ}{ }^{\circ}$ Jot̃o Chaves Campello.

D. ${ }^{\text {or }}$ Vice Presidente dela Provincia en ejercicio.

Benito Maurell. 